\title{
PDMS-SiO $-\mathrm{TiO}_{2}-\mathrm{CaO}$ hybrid materials - biocompatibility and
}

\section{nanoscale surface features}

J. Carlos Almeida ${ }^{a}$, András Wacha ${ }^{b}$, Pedro S. Gomes ${ }^{d}$, M. Helena R. Fernandes ${ }^{d}$, M. Helena Vaz Fernandes ${ }^{a}$, Isabel M. Miranda Salvado ${ }^{a,{ }^{*}}$

${ }^{a}$ CICECO - Aveiro Institute of Materials, Department of Materials and Ceramic Engineering, University of Aveiro, 3810193 Aveiro, Portugal

${ }^{b}$ Research Centre for Natural Sciences, Hungarian Academy of Sciences, Magyar Tudósok körútja 2, Budapest, 1117 Hungary

'Laboratory for Bone Metabolism and Regeneration, Faculdade de Medicina Dentária, Universidade do Porto, Portugal

* Corresponding author at: Tel.: +351 234370354; fax: +351 234370204; E-mail address: isabelmsalvado@ua.pt

Keywords: sol-gel, hybrid materials, hydrophobicity, biocompability

\section{Abstract}

Two biocompatible $\mathrm{PDMS}-\mathrm{SiO}_{2}-\mathrm{TiO}_{2}-\mathrm{CaO}$ porous hybrid materials were prepared using the same base composition, precursors, and solvents, but following two different sol-gel procedures, based on the authors' previous works where for the first time, in this hybrid system, calcium acetate was used as calcium source. The two different procedures resulted in monolithic materials with different structures, microstructures, and surface wettability. Even though both are highly hydrophobic (contact angles of $127.2^{\circ}$ and $150.6^{\circ}$ ), and present different filling regimes due to different surface topographies, they have demonstrated to be biocompatible when tested with human osteoblastic cells, against the accepted idea that high-hydrophobic surfaces are not suitable to cell adhesion and proliferation. At the nanoscale, the existence of hydrophilic silica domains containing calcium, where water molecules are physisorbed, is assumed to support this capability, as discussed.

\section{Introduction}

The search for a material with mechanical properties close to those of human bone produced a new family of hybrid materials that take advantage of the synergy between inorganic silica $\left(\mathrm{SiO}_{4}\right)$ domains, based on sol-gel bioactive glass compositions, and organic polydimethylsiloxane, PDMS $\left(\left(\mathrm{CH}_{3}\right)_{2} \cdot \mathrm{SiO}_{2}\right)_{n}$, 
domains. After the first attempt to produce a potential osteoinductive ormosil (organically modified silicate) [1], several studies have been reported in the literature [2-7] on $\mathrm{PDMS}^{-\mathrm{SiO}_{2}}$ compositions containing calcium, showing the correlations between the microstructural evolution and the experimental conditions of synthesis (water and acid content, PDMS molecular weight, etc.). A surface calcium-phosphate forming ability was accepted as an indicator of potential bioactivity [8].

High PDMS amounts may however hinder the incorporation of $\mathrm{Ca}^{2+}$ ions into the silica substructure, decreasing the potential for bioactivity, as observed by Salinas et al. [6] that reported an optimum $\mathrm{Ca}^{2+}$ :TEOS (tetraethyl orthosilicate) molar ratio of 0.1:1.

Titanium was first added to the PDMS-SiO ${ }_{2}-\mathrm{CaO}$ system by Chen et al. [9] in order to change its mechanical properties, while also having in mind that the presence of titanium could increase the bioactivity, due to surface $\mathrm{Ti}-\mathrm{OH}$ groups [10]. The authors observed that the bioactivity of hybrids increased with decreasing PDMS content and increasing $\mathrm{TiO}_{2}$ content, and that the strain at failure increased with increasing PDMS content and decreasing $\mathrm{TiO}_{2}$ content, respectively.

Besides its importance as an inducing agent for the precipitation of surface calcium phosphates, titanium can have an effect on the condensation of the siloxane units leading to the formation of longer PDMS chains together with oxide based particles [11] and also influencing the final morphology of PDMS$\mathrm{SiO}_{2}-\mathrm{TiO}_{2}$ xerogels [12].

In the last years one of the major drawbacks pointed to these osteoinductive hybrid materials [8] has been the use of calcium nitrate as the calcium source in sol-gel processing, since nitrates are potentially harmful due to the toxicity associated with the formation of nitrate derived by-products $[13,14]$. In order to prevent this, a thermal step using temperatures above $400^{\circ} \mathrm{C}$ is essential, which may lead to thermal degradation of the materials prepared [15]. Other calcium sources were tried, such as calcium chloride or calcium methoxyethoxide, but some processing related problems still persisted [8]. In a previous work our group used calcium acetate as an alternative calcium source for $\mathrm{PDMS}-\mathrm{SiO}_{2}$ based hybrids and produced a potential bioactive material [16], 
as suggested from immersion tests in a synthetic physiological fluid. Although the $\mathrm{PDMS}_{-} \mathrm{SiO}_{2}-\mathrm{CaO}$ hybrid system has been appointed as a potentially promising system for biomedical applications in bone substitutes, no information exists in the literature about its cytocompatibility in the presence of osteoblastic cells.

In the present work, the authors intend to give some clues on the ways of modulating the microstructure and some surface features (roughness and wettability) of these materials and assess its cytocompatibility. For this, two PDMS-SiO $2-\mathrm{TiO}_{2}-\mathrm{CaO}$ porous hybrid materials were prepared with the same amounts of precursors and solvents, but using two different approaches for the sol-gel procedure based on the authors' previous works [12,16,17]. The materials' structures and microstructures were analyzed by Fourier Transform Infrared Spectrometry (FT-IR), solid state Nuclear Magnetic Resonance (NMR) techniques, Small-angle X-ray Scattering (SAXS), nitrogen adsorption and Scanning Transmission Electron Microscopy (STEM). Surface roughness and wettability were studied by 3D optical profilometry and by contact angle measurements respectively. Bioactivity was evaluated in vitro by immersion of the materials in Kokubos's [18] simulated body fluid (SBF) and posterior surface analysis by different techniques as well as supernatant liquid analysis by Inductively Coupled Plasma spectroscopy (ICP). Cytocompatibility was assessed from the response of MG63 osteoblastic cells characterized in terms of cell proliferation, alkaline phosphatase activity and morphology, observed by Scanning Electron Microscopy (SEM) and Confocal Laser Scanning Microscopy (CLSM).

\section{Materials and methods}

\subsection{Sample preparation}

The following reagents were used for samples preparation: tetraethyl orthosilicate (TEOS), polydimethylsiloxane (PDMS) silanol terminated (550 g $\mathrm{mol}^{-1}$ average molecular weight), isopropanol (IPA), calcium acetate monohydrate $\left(\mathrm{Ca}\left(\mathrm{CH}_{3} \mathrm{CO}_{2}\right)_{2} \cdot \mathrm{H}_{2} \mathrm{O}\right)$, titanium isopropoxide ( $\left.\mathrm{TiPr}\right)$, all from SigmaAldrich, and ethyl acetoacetate (EtAcAc) from Merck. The composition of the 
materials, in molar ratio, is shown in Table 1 for two types of samples designated by $I$ and $K$.

Two different preparation procedures were used: procedure $I$ and procedure $K$ (Figure 1). In procedure $I$, already discussed in previous works [12,19], an aqueous solution of $\mathrm{Ca}\left(\mathrm{CH}_{3} \mathrm{CO}_{2}\right)_{2} \cdot \mathrm{H}_{2} \mathrm{O}$ (the amount of water used was only the required to dissolve the acetate) was added to a mixture of TEOS, PDMS and the remaining $\mathrm{H}_{2} \mathrm{O}$. Afterwards, isopropanol was added and the medium was acidified with $\mathrm{HCl}$. The prepared solutions were then stirred for 2 hours. After that TiPr, previously chelated with EtAcAc using a 1:2 propoxide/chelating agent molar ratio, was added to the solution. The final mixture was then stirred for another 3 hours at room temperature and then poured into $15 \mathrm{~mm}$ diameter polyethylene cylindrical containers.

Table 1: Samples composition

Notation Composition (molar ratio/TEOS)

$\begin{array}{llllll}\text { TEOS } & P D M S & \mathrm{H}_{2} \mathrm{O} & \mathrm{HCl} & \mathrm{Ca} & \mathrm{Ti}\end{array}$

Sample I

Sample $K$

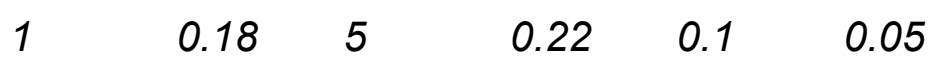

[Note from the authors: the letter "I" was used in a previous work and maintained to facilitate comparison with prior results; the letter "K" comes from the word különbözö that mean "different" in Hungarian.]

In procedure $K$ PDMS was first put to react with $\operatorname{TiPr}$ (previously chelated as in procedure I) in an IPA medium [17]. A second solution was prepared by adding an aqueous solution of calcium acetate to TEOS, previously dissolved in IPA, and finally acidified with $\mathrm{HCl}$. Then this solution was mixed with the first one and stirred for 60 minutes, after which it was poured into the $15 \mathrm{~mm}$ diameter polyethylene cylindrical containers.

For both procedures, the mixtures were kept for a week at room temperature for gelation and then placed in an oven at $60^{\circ} \mathrm{C}$ for another week for aging. After this the gels were dried at $150^{\circ} \mathrm{C}$ for $24 \mathrm{~h}$. Monolithic samples with the shape of cylinders were obtained without visible cracks. Cylinders were cut into disks 
with a diameter of ca. $15 \mathrm{~mm}$ and thickness of ca. $1.5 \mathrm{~mm}$ using a Struers Secotom-10 cutting machine.

\section{I procedure}

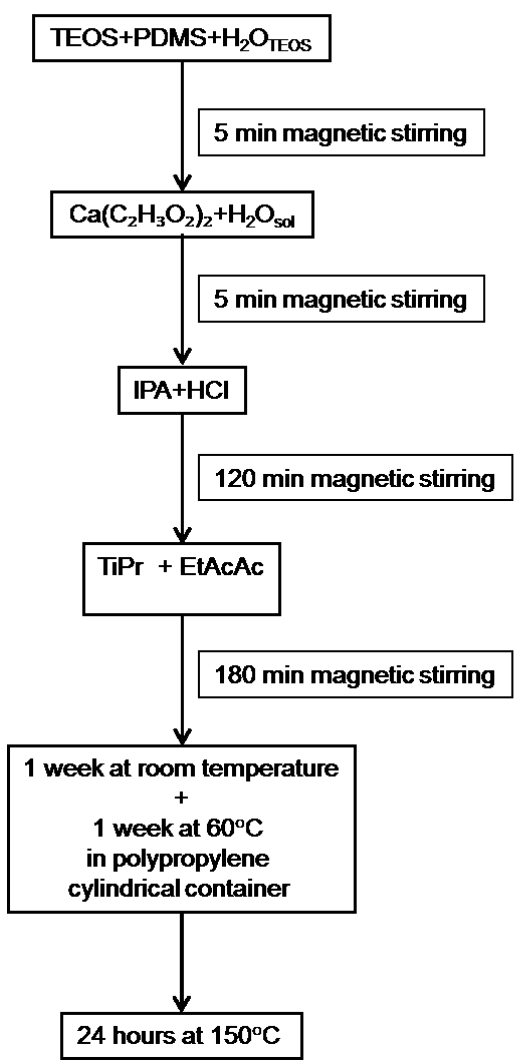

K procedure

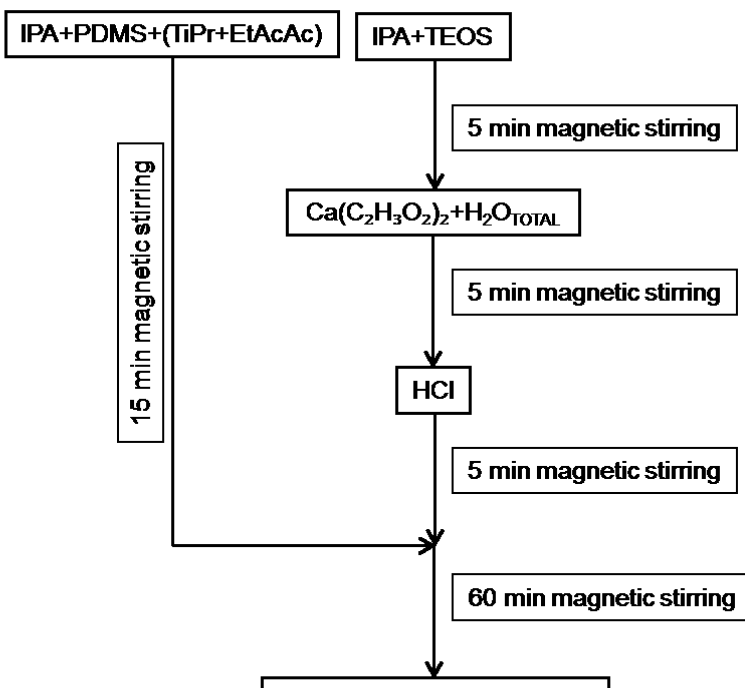

1 week at room temperature

1 week at $60^{\circ} \mathrm{C}$

in polypropylene cylindrical container

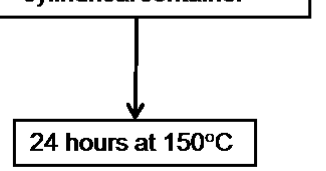

Figure 1: Experimental procedures used: procedure I (left) and procedure $K$ (right).

\subsection{FT-IR and solid-state NMR spectroscopy}

Samples were first crushed in a mortar in order to create fine powders and were analysed by FT-IR spectroscopy, ${ }^{1} \mathrm{H}$ MAS (magical angle spinning), ${ }^{29} \mathrm{Si}$ MAS and ${ }^{29} \mathrm{Si}-\left\{{ }^{1} \mathrm{H}\right\}$ CP-MAS (cross-polarization magical angle spinning) NMR, using the experimental conditions described in a previous work [12]. The CP-MAS spectra were simulated using DMFIT [20] and data available from the literature [21-24] was used for the peaks assigned to $\left(\mathrm{CH}_{3}\right)_{2} \mathrm{SiO}_{2}$ difunctional $D^{n}(n=1,2)$ structural units, $\mathrm{SiO}_{4}$ tetrafunctional $\mathrm{Q}^{n}(n=3,4)$ structural units, where $n$ is the number of bridging oxygen atoms surrounding $\mathrm{Si}$, and crosslinked $\mathrm{D}_{(\mathrm{Q})}$ 
structural groups. A quantitative analysis of the structural units was obtained by fitting the MAS-NMR spectra, using the set of signals extracted from $\mathrm{CP}$ experiments, and calculating the relative percentage from the area of each fitted signal. For each structural group, $\mathrm{D}$ and $\mathrm{Q}$, the value of relative intensity $\left(\% I_{R}\right)$ of its component structural units was determined.

\subsection{Small angle $X$-ray scattering (SAXS)}

SAXS measurements were carried out at the CREDO instrument [25] of the Research Centre for Natural Sciences (Budapest, Hungary) using photons of $1.5418 \AA$ wavelength ( $\mathrm{Cu} \mathrm{Ka}$ characteristic radiation). Scattering patterns recorded at two sample-to-detector distances: 456.769 and $1217.81 \mathrm{~mm}$ were corrected and calibrated using the standard on-line data reduction procedures implemented in the instrument control software. Azimuthal averaging of the scattering patterns was applied to produce the scattering curves. The curves obtained at different sample-to-detector distances were merged in order to produce a single curve for each sample, covering the whole attainable range of $q$ (the magnitude of the scattering variable, defined as $q=4 \pi \sin (\theta / \lambda)$, where $2 \theta$ is the scattering angle and $\lambda$ is the wavelength).

\subsection{Surface area $(B E T)$}

For each composition, the surface area was characterized by nitrogen adsorption using a Micromeritics - Gemini equipment. Samples were degassed at $150^{\circ} \mathrm{C}$ for 12 hours and cooled to room temperature. At least 30 points were acquired with an equilibration time set of 5 seconds. Specific surface areas were obtained from the nitrogen isotherms, using the Brunauer-Emmet-Teller (BET) method [26]. Micropore surface areas were obtained using the t-plot method [27].

\subsection{Surface topography analysis}

Surface topography of cut discs was evaluated using a 3D optical variation system IFM G4 (Alcona). Line and area measurements were done according to 
the recommendations described by the ISO standards 4287,4288 and 25178 . The parameters required for the studies on cell adhesion and proliferation were measured: arithmetic mean deviation of the surface $\left(R_{a}\right)$, root-mean-square deviation of the surface $\left(R_{q}\right)$, maximum height of summits $\left(R_{p}\right)$, maximum depth of valleys $\left(R_{v}\right)$, and total height of the surface $\left(R_{t}\right)$. In addition, the fractal dimension $\left(D_{f}\right)$ and the developed area ratio $\left(S_{d r}\right.$, ratio between the interfacial and the projected area) were also calculated.

\subsection{Static contact angle}

Contact angle measurements were performed using the sessile drop method in a contact angle meter OCA15+ (DataPhysics Instruments) with highperformance image processing system. Drops of distilled water, with a volume of $2 \mu \mathrm{L}$ and $10 \mu \mathrm{L}$ were added by a motor driven syringe, at room temperature. Five measurements were taken in different regions of 3 cut discs for each composition and an averaged value was calculated.

According to Wenzel model $[28,29]$ roughness increases the surface area of a solid, enhancing its hydrophobicity. Moreover, air can remain trapped below the drop, leading to a super hydrophobic behavior, in which the drop sits partially on air creating a non-filling regime where the liquid does not penetrate into surface grooves (Cassie-Baxter model) [28]. Depending on the applied model (filling or non-filling regime) Young contact angle $\left(\theta_{Y}\right)$ values can be calculated using the Wenzel equation [29] described by

$$
\cos \theta_{m}=R_{W} \cos \theta_{Y}
$$

where $R_{W}$ symbolizes the surface area ratio, also referred to as Wenzel factor and calculated by

$$
R_{W}=1+S_{d r} / 100
$$

and $\theta_{m}$ is the measured (also called apparent) contact angle, or using the Cassie-Baxter equation [29] described by

$$
\cos \theta_{m}=-1+\varphi_{\mathrm{S}}\left(1+\cos \theta_{Y}\right)
$$

where $\varphi_{s}$ is the fraction of solid in contact with the liquid. 


\subsection{In vitro evaluation}

\subsubsection{Bioactivity studies}

The ability of the materials to precipitate calcium-phosphate on its surface was evaluated in vitro by immersion of the samples in Kokubos's [18] simulated body fluid (SBF) for 3,7 and 14 days. The surface of the dried samples after soaking was observed by Scanning Transmission Electron Microscopy (STEM) (Hitachi SU-70) using an accelerating voltage of $25 \mathrm{kV}$, equipped with an Electron Dispersive Spectroscopy (EDS) apparatus (Bruker QUANTAX 400). Grazing Incidence X-Ray Diffraction (GIXRD) analysis of surfaces was performed using a PanAlytical X'Pert Pro instrument $(\mathrm{Cu}-\mathrm{K} \alpha$ radiation = $1.5418 \AA$ ) configured with a parallel mirror in the incident beam and a parallel plate collimator in the diffracted beam path to allow a constant low-angle angle incidence $\left(2^{\circ}\right)$ glancing the sample surface. The X-ray measurements were taken at $45 \mathrm{kV}, 40 \mathrm{~mA}$ in a $2 \theta$ range from $3^{\circ}$ to $50^{\circ}$, with $0.026^{\circ}$ step size. The concentrations of $\mathrm{Ca}$ and $\mathrm{P}$ in the supernatant liquid were determined by inductively coupled plasma (ICP) (Jobin-Yvon JY70 Plus spectrometer).

\subsubsection{Osteoblastic cytocompatibility}

Sample discs were sterilized using gamma irradiation dose of $25 \mathrm{kGy}$, the dose usually recommended [30,31] to achieve a Sterility Assurance Level (SAL) of $10^{-6}$ and a procedure already described [19].

Human osteoblastic-like MG63 cells (ATCC number CRL-1427 TM), of passage 25 were cultured in $\alpha-M E M$, supplemented with $10 \%$ fetal bovine serum, 50 $\mu \mathrm{g} \cdot \mathrm{ml}^{-1}$ ascorbic acid, $50 \mu \mathrm{g} \cdot \mathrm{ml}^{-1}$ gentamicin and $2.5 \mu \mathrm{g} \cdot \mathrm{ml}^{-1}$ fungizone, at $37^{\circ} \mathrm{C}$, in a humidified atmosphere of $5 \% \mathrm{CO}_{2}$ in air. For sub-culturing, the cell layer (at around $70-80 \%$ confluence) was detached with trypsin - EDTA solution $(0.05 \%$ trypsin, $0.25 \%$ EDTA; 5 minutes, $37^{\circ} \mathrm{C}$ ). The cell suspension was used in the experiments. 
Cells were seeded over the materials' samples, at a density of $2 \times 10^{4}$ cells. $\mathrm{cm}^{-2}$, and were cultured for 8 days. Cell behavior was characterized throughout the culture time for cell proliferation, alkaline phosphatase (ALP) activity, cell morphology and F-actin cytoskeleton immunostaining.

DNA content. Cell proliferation was evaluated by analyzing the DNA content, using the PicoGreen DNA quantification assay (Quant-iT TM PicoGreenR dsDNA Assay Kit, Molecular Probes Inc., Eugene). At each time-point, culture medium was removed and the cultures were treated with Triton X-100 (Sigma, 0.1\%, 5 $\mathrm{min}$ ) to lyse the cell layer. DNA was assessed in the cellular lysates, according to manufacturer's instructions. Fluorescence was measured on an ELISA reader (Synergy HT, Biotek) at wavelengths of 480 and $520 \mathrm{~nm}$, excitation and emission respectively, and corrected for fluorescence of reagent blanks. The amount of DNA was calculated by extrapolating a standard curve obtained by running the assay with the given DNA standard.

ALP activity. ALP activity was evaluated in cell lysates $(0.1 \%$ Triton X-100, 5 $\min$ ) by the hydrolysis of $p$-nitrophenyl phosphate in alkaline buffer solution $\left(\mathrm{pH} 10.3 ; 30 \mathrm{~min}, 37^{\circ} \mathrm{C}\right)$ and colorimetric determination of the product ( $p$ nitrophenol) at $400 \mathrm{~nm}$ in an ELISA plate reader (Synergy HT, Biotek). ALP activity was normalized to total protein content (quantified by Bradford's method) and was expressed as $\mathrm{nmol} / \mathrm{min} \mu$ gprotein $^{-1}$.

F-actin cytoskeleton. Seeded material samples were fixed $(3.7 \%$ paraformaldehyde, $15 \mathrm{~min}$ ), and were stained for the cell cytoskeleton filamentous actin (F-actin). Cultures were treated with Alexa Fluor 488 Phalloidin (1:20 dilution in PBS, $1 \mathrm{~h}$ ) and counterstaining with propidium iodide $\left(1 \mu \mathrm{g} \cdot \mathrm{ml}^{-1}, 10 \mathrm{~min}\right)$ for cell nuclei labelling. Labelled cultures were mounted in Vectashield $\circledast$ and examined under Confocal Laser Scanning Microscopy (CLSM; Leica SP2 AOBS, Leica Microsystems).

SEM observation. Seeded material samples were fixed $(1.5 \%$ glutaraldehyde in $0.14 \mathrm{M}$ sodium cacodylate buffer, $\mathrm{pH}=7.3,10 \mathrm{~min}$ ), dehydrated in graded alcohols, critical-point dried, sputter-coated with an Au/Pd thin film (SPI Module Sputter Coater equipment), and observed under a high resolution (Schottky) environmental scanning electron microscope (Quanta 400 FEG ESEM). 
Statistical analysis: Three independent experiments were performed; in each experiment, three replicas were accomplished for the biochemical assays and two replicas for the qualitative assays. Results are presented as mean \pm standard deviation (SD). One-way analysis of variance (ANOVA) was used in combination with Bonferroni's post-hoc test to data evaluation. Values of $p \leq$ 0.05 were considered significant.

\section{Results and discussion}

\subsection{FT-IR analysis}

Figure 2 shows the FT-IR spectra obtained for both $I$ and $K$ samples, which exhibit bands in the $400-3600 \mathrm{~cm}^{-1}$ region, previously reported as characteristic of PDMS-SiO $2-\mathrm{TiO}_{2}$ and PDMS-SiO $2-\mathrm{CaO}[16,15,17]$ hybrid materials.

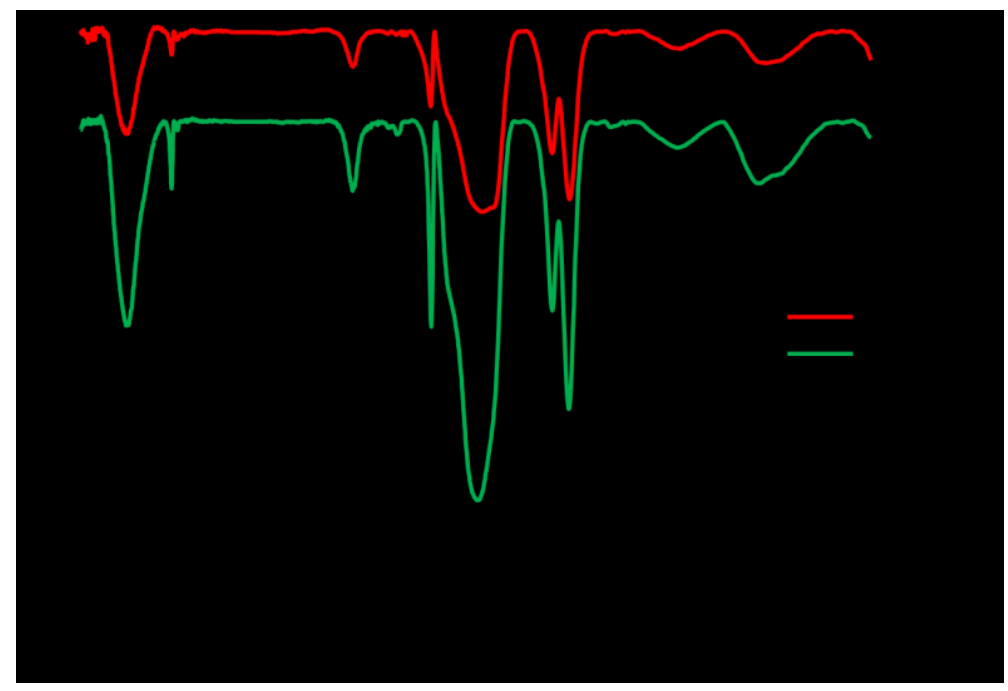

Figure 2: FT-IR spectra of sample I and sample $K$

Bands attributed to the presence of hybrid cross-linked $\mathrm{SiO}_{2}$ ( $Q$ units) - PDMS (D units) structures [32,33] are observed at ca. $430 \mathrm{~cm}^{-1}$ and $850 \mathrm{~cm}^{-1}$. The first frequency value has been reported to be related with the continuous interruption of silica network with hybrid $\mathrm{SiO}_{4}-\left(\mathrm{CH}_{3}\right)_{2}$. $\mathrm{SiO}_{2}$ or oxo-metal linkages, once it is downshifted when compared to values obtained for pure silica gel (usually near $460 \mathrm{~cm}^{-1}$ ). In a similar way, the presence of $D-Q$ hybrid bonds explains the downshift of the frequency assigned to the symmetrical vibration of $\mathrm{CH}_{3}$ groups, 
once pure PDMS chains exhibit a weak band at $860 \mathrm{~cm}^{-1}$, assigned to the symmetrical rocking of $\mathrm{CH}_{3}$ groups.

Some differences are also observed in the configuration of the region between 1000 and $1250 \mathrm{~cm}^{-1}$, assigned to asymmetric stretching of Si-O-Si bonds in both $D$ and $Q$ groups. According to the literature, those differences indicate some variations in the geometry and size of the siloxane condensed species [34,35], which are dependent on the sol-gel experimental parameters [36] and on the type of metal introduced into the system [35].

The existence of adsorbed water is confirmed in all compositions by the presence of bands at ca. $3450 \mathrm{~cm}^{-1}$ and $1640 \mathrm{~cm}^{-1}$, corresponding to the deformation and bending vibrational modes of $\mathrm{O}-\mathrm{H}$ bonds, respectively [34]. A weak signal at ca. $950 \mathrm{~cm}^{-1}$ is assigned to the symmetrical stretching of $\mathrm{Si}-\mathrm{OH}$ bonds [37].

Probably due to the relatively small quantities of Ti used, the bands assigned to the Si-O-Ti at ca. $930 \mathrm{~cm}^{-1}[38,39]$ were not observed.

No C-O vibrational modes, from calcium acetate were detected due to the fact that during the sol-gel preparation the acetic acid (produced by the protonation of the carboxylic group of calcium acetate in the highly acidic medium used in the synthesis) reacts with the excess of 2-propanol present originating an ester (2-propyl ethanoate), which has a boiling point lower than the temperatures used here to produce the samples [40].

\subsection{Solid-State ${ }^{1}$ H NMR MAS, ${ }^{29}$ Si NMR MAS and ${ }^{29}$ Si- $\left\{{ }^{1} H\right\} N M R$ CP-MAS analysis}

The samples $I$ and $K$ were analyzed by ${ }^{1} \mathrm{H}$ MAS NMR and the results are presented in Figure 3. The spectra present a peak between 0.08 and 0.13 ppm assigned to $\mathrm{CH}_{3}$ groups. Its broadness is explained by changes in the mobility of $\mathrm{CH}_{3}$ groups due to the vicinity of $\mathrm{Q}$ (or other metal-oxide) units, in a more rigid cross-linked $D-Q$ structure [21,41]. A shoulder near $1.2 \mathrm{ppm}$, usually assigned to isolated, water-inaccessible silanols $[41,42]$ is observed in both. $A$ 
sharp peak at ca. $4.8 \mathrm{ppm}$ is assigned to physisorbed water molecules $[41,43]$, probably related to the inclusion of $\mathrm{Ca}$ into the composition of the hybrids. No physisorbed water was detected in our previous studies [12] were the structure of $\mathrm{PDMS} \mathrm{SiO}_{2}$ hybrids without $\mathrm{Ca}$ was also analysed by ${ }^{1} \mathrm{H}$ MAS-NMR. Leonova et al. [43] and Gunawidjaja et al. [44] reported the presence of physisorbed water due to the presence of $\mathrm{Ca}$ in bioglass compositions. Gunawidjaja et al. [44] emphasized that the higher the Ca content, the stronger and broader will be the signal around $5 \mathrm{ppm}$ also accompanied by a downfield of the chemical shift. Because both compositions have the same overall $\mathrm{Ca}$ content, the observed differences in the broadness of those peaks in Figure 3 can be related to the $\mathrm{Ca}^{2+}$ concentration in the surface.

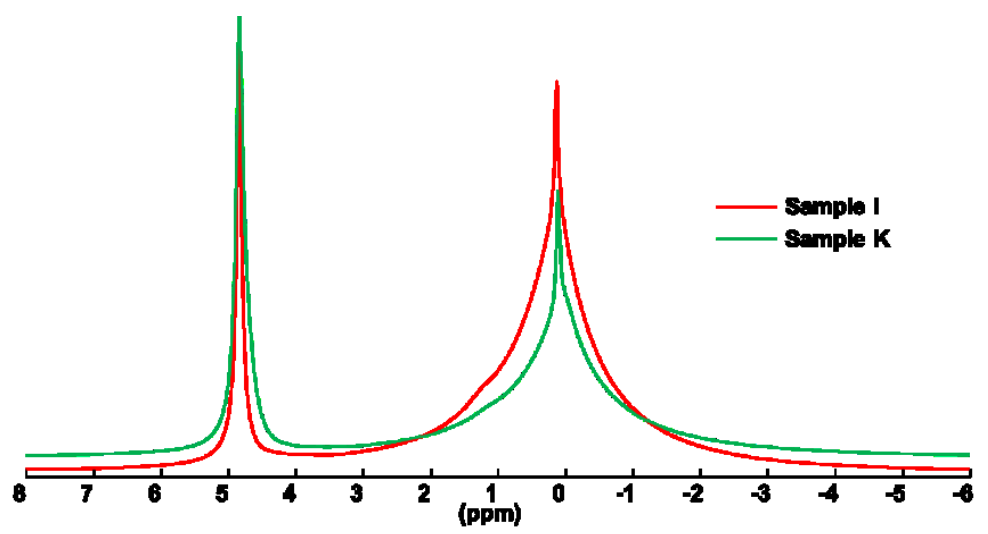

Figure $3:{ }^{1}$ H MAS NMR spectra for both type of samples.

${ }^{29} \mathrm{Si}$ MAS-NMR studies were performed on both types of samples and the results are shown in Figure 4a. Two distinct groups of Si structural units are observed, one with chemical shifts between -15 to $-23 \mathrm{ppm}$, assigned to dimethylsiloxane $\mathrm{D}$ structural units $\left(\left(\mathrm{CH}_{3}\right)_{2} \cdot \mathrm{SiO}_{2}\right)$, and another with chemical shifts between -80 to $-110 \mathrm{ppm}$, assigned to $\mathrm{Q}$ structural units $\left(\mathrm{SiO}_{4}\right)$ [22]. $\mathrm{A}$ quantitative analysis (Table 2) of the different structural units was obtained for both samples by fitting the ${ }^{29} \mathrm{Si}$ MAS NMR spectra, using the set of signals extracted from ${ }^{29} \mathrm{Si}-\left\{{ }^{1} \mathrm{H}\right\}$ cross-polarization MAS-NMR experiments (Figure 4b) as explained in section 2.2. The fitting was obtained using four or five signals to simulate the $D$ region and four signals to simulate the $Q$ region. 
The first three signals in the $D$ region, $D_{a}, D_{b}$ and $D_{c}$, with values of chemical shift between -17.0 ppm and -20.4 ppm, have been assigned in the literature to $\mathrm{D}$ units cross-linked to oxide-based structures in PDMS-SiO 2 [21,23,24,41,45], and $\mathrm{PDMS}^{-\mathrm{TiO}_{2}}[35,46]$ systems. The deviation of the chemical shift arising from pure D units of PDMS (near -23 ppm) is due to the nature of the first, and even of the second, neighboring atom. The downfield (and the respective broadness of the peak) is explained by the lower mobility of dimethylsiloxane units at the end of PDMS chains close to metal-oxo nanoparticles [21,35]. The higher chemical shift is assigned to the presence of "short" siloxane chains isolated between those nanoparticles. Thus, $D_{a}$ signals are due to a monomer $D$ unit linking two $Q$ units, in $Q D Q$ arrangement. $D_{b}$ signals are due to a dimethylsiloxane dimer, or trimer, linked to $Q$ units in a $Q D D Q$, or $Q D D D Q$ arrangement, respectively. $D_{c}$ signals are due to a $D$ unit located between a $Q$ unit and a longer (more than 3 units) PDMS chain [21]. The two other signals, $D_{d}$ and $D_{e}$ (narrower than the other signals) are assigned to $D$ units located in different positions inside the PDMS chains, in a less constrained environment in short PDMS chains containing about 5 dimethylsiloxane units [21]. The signal from those higher mobile structural units, like $D_{e}$, is not present in the ${ }^{29} \mathrm{Si}-\left\{{ }^{1} \mathrm{H}\right\}$ CP-MAS spectra due to the lack of efficiency of the cross-polarization (CP) sequence [47].

Table 2 shows some differences in the distribution of the siloxane structures of the different hybrids. Sample / presents more $Q$ units linked by a D monomer, in a Q-D-Q configuration, while sample $K$ does not shows any, but a clear predominance of $D_{b}$ structural units. Recalling the different preparation procedures of both, in the case of sample $K$ titanium alkoxide was first reacted with the hydroxyl terminated PDMS without the presence of water and $\mathrm{HCl}$. It is known from our previous work [12] that some dimethylsiloxane monomers resulted from the cleavage of hydroxyl terminated PDMS dimers in highly acidic aqueous medium [48]. In the case of $K$ preparation, those $\mathrm{D}_{\mathrm{OH}}^{1}-\mathrm{D}_{\mathrm{OH}}^{1}$ dimers, using the notation defined by Glaser et al. [22], will react first with the TiPr propoxide being not cleaved when they are subsequently added to an acidic medium. 

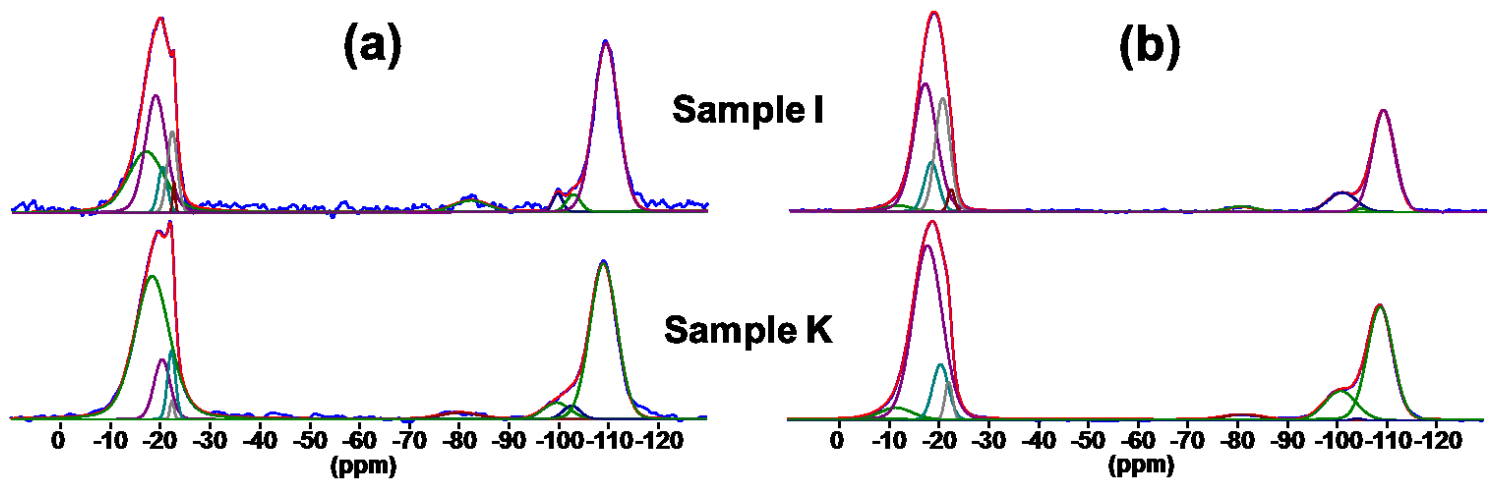

Figure 4: (a) ${ }^{29}$ Si MAS NMR and (b) ${ }^{29}$ Si- $\left\{{ }^{1} H\right\}$ CP-MAS NMR spectra for both type of samples.

When analysing the distribution of silica based structures the predominance of full condensed $Q^{4}$ structures can be observed in all compositions, which is in line with the authors previous works [15]. Brus [41] reported in a structural study of hybrid materials prepared from dimethyldiethoxysilane (DMDES) and TEOS that using an increased DMDEOS/TEOS molar ratio produced more crosslinked $D-Q$ bonds and resulted in a decrease in the $Q^{3} / Q^{4}$ ratio. Consequently, the total condensation rate of siloxane network increased. Comparing in Table 2 the distribution of structural units, it is observed that a higher number of very short hybrid structures $\left(D_{A}\right)$ (I sample) is not followed by a corresponding lower number of $Q^{3}$ or $Q^{1}$ structures. These differences can be explained by the authors' previous findings [15], namely that some of the less condensed $Q$ structures, $Q^{3}$ and $Q^{1}$, are not only associated with hydroxyl groups, but also with titanium and calcium. 
Table 2: Chemical shift $\delta(p p m)$, relative intensities (\%l) and full width at high maximum (FWHM (ppm)) of the different structural units after simulations of the ${ }^{29}$ Si NMR MAS data.

\begin{tabular}{|c|c|c|c|c|}
\hline \multirow{2}{*}{$\begin{array}{c}\text { structural } \\
\text { units }\end{array}$} & \multicolumn{2}{|r|}{ Sample I } & \multicolumn{2}{|c|}{ Sample K } \\
\hline & $\%$ & $\begin{array}{c}\delta /[\mathrm{FWHM}] \\
(\mathrm{ppm})\end{array}$ & $\% 1$ & $\begin{array}{c}\delta /[\mathrm{FWHM}] \\
(\mathrm{ppm})\end{array}$ \\
\hline$\overline{D_{a}}$ & 21.8 & $-17.0[8.5]$ & & \\
\hline$D_{b}$ & 23.3 & $-18.9[5.0]$ & 42.8 & -18.4 [8.3] \\
\hline $\mathrm{D}_{\mathrm{c}}$ & 3.6 & $-20.3[2.1]$ & 7.6 & -20.4 [3.8] \\
\hline$D_{d}$ & 7.0 & $-22.3[2.4]$ & 4.3 & $-22.3[1.9]$ \\
\hline$D_{e}$ & 0.7 & $-22.6[0.6]$ & 0.6 & $-22.4[0.9]$ \\
\hline$Q^{1}$ & 3.6 & $-82.3[8.2]$ & 2.3 & $-80.3[9.3]$ \\
\hline$Q^{3}{ }_{a}$ & 1.5 & $-99.7[2.3]$ & 3.7 & -99.7 [6.3] \\
\hline$Q_{b}^{3}$ & 2.2 & $-102.9[3.4]$ & 2.0 & $-102.7[4.0]$ \\
\hline$Q^{4}$ & 37.4 & $-109.5[5.8]$ & 36.8 & $-109.2[6.4]$ \\
\hline
\end{tabular}

In order to obtain a better understanding of the nature of the $\mathrm{Q}^{3}$ groups, ${ }^{29} \mathrm{Si}$ $\left\{{ }^{1} \mathrm{H}\right\}$ CP-MAS NMR spectroscopy was performed. This technique has been used as a valuable technique to study $\mathrm{PDMS}-\mathrm{SiO}_{2}$ based hybrid systems, taking advantage of the magnetization transfer between abundant ${ }^{1} \mathrm{H}$ and rare ${ }^{29} \mathrm{Si}$ spins due to the presence of protonated groups directly bonded to some $\mathrm{Si}$ structural units [49]. From the observation of MAS and CP-MAS spectra (Figure $4 a$ and $4 b$ ) it is clear that there are two different peaks in the zone normally assigned to $Q^{3}$ structures, denoted by $Q^{3}{ }_{a}$ and $Q^{3}{ }_{b}$. When comparing the relative intensities of these peaks in the MAS and in the CP-MAS spectra it is obvious that $Q^{3}$ becomes more intense in the cross-polarization mode and $Q^{3}{ }_{b}$ almost disappears. The values of the $Q^{3}{ }_{a}$ and $Q^{3}{ }_{b}$ chemical shifts are shown in Table 2. Brus [41] observed that, for hybrid samples prepared from TEOS and DMDEOS (dimethyldiethoxysilane), an increase of the DMDEOS:TEOS ratio from 0 to 2 resulted in a clear downfield of the $Q^{3}$ signals. Other important 
information from the comparison between MAS and CP-MAS spectra is the maintenance of the $Q^{4}$ signal as the dominant one in the $Q$ region. In addition to the evidence of the existence of a homogeneous structure, it is also a good indication that the size of the primary silica domains is not much bigger than 10 $\AA$ [22]. Thus $Q^{3}$ a structures are probably near the surface of the silica domains where hybrid bonds are located. Considering that both $Q^{3}{ }_{a}$ and $Q^{3}{ }_{b}$ can be a sum of different moieties linked to a $Q^{3}$ structure $(\mathrm{OH}, \mathrm{Ca}$ or $\mathrm{Ti})$, it can be assumed that the loss of $\mathrm{Q}^{3}$ b signal in the CP mode is due to the existence of $\mathrm{Ca}$ and/or Ti in silica surfaces.

In the preparation of $K$ samples, TEOS was first hydrolysed using an aqueous solution of calcium acetate. As in the case of sample $I$, when comparing the NMR spectra of sample $K$ in the single pulse mode (Figure $4 a$ ) with the corresponding spectra obtained in the cross-polarization mode (Figure $4 \mathrm{~b}$ ), the $Q^{3}{ }_{b}$ peak almost disappears, indicating that the $Q^{3}{ }_{b}$ signal may also be related with calcium and/or titanium. In both $I$ and $K$ samples the CP mode evidenced a peak at ca. $-12 \mathrm{ppm}$ assigned [35] to $D$ units linked to transition metal domains, which is not observed in the single pulse spectra. The relatively higher intensity of this peak in sample $K$ can be an indication that a higher number of Ti-oxo domains are linked to $D$ units when compared with sample $I$.

\subsection{Small angle $X$-ray scattering}

Small angle scattering techniques have been used to obtain valuable information about the structures of hybrid materials at nano and micro scales, giving a better understanding of the sol-gel process [36].

Sol-gel derived nanostructures can be described by fractal geometry, insofar as they exhibit similar morphology at different scales (self-similarity). When aggregates or polymeric structures are formed they can be described by a mass fractal dimension $D_{m}$, which is defined as the exponent that relates the mass $M$ of an object to its linear size $R$ :

$$
M \sim R^{D_{m}}
$$

When a structure is uniformly dense (non-polymeric or colloidal) it can be described by a surface fractal: 


$$
S \sim R^{D_{S}}
$$

$S$ being the surface area of the structure and $D_{s}$ its surface fractal dimension. For fractal surfaces $D_{s}$ vary between 2 and 3 , thus it is a measure of roughness. In the limit of a smooth object, the surface can be approximate by a plane (bidimensional), therefore $D_{s}=2$.

Small angle X-ray scattering (SAXS) was performed for the two different samples, $I$ and $K$, and the results are presented in Figure 5 and Table 3. As powder samples are generally very strong scatters, scattering signals with good statistics were easily obtained, with three different regions in the log-log plot of scattering intensities $I(q)$ versus $q$, the modulus of the scattering vector. At low values of $q$ the scattering plots present a region where the intensity can be described by a simple power-law equation

$$
I(q)=A / q^{d}+\text { background }
$$

where $d$ is related to the fractal dimension (for mass fractals $d<3$, for surface fractals $3<d<4$, and for diffuse interfaces $d>4$ ) and a pre-factor $A$. For mass fractals, $d$ is simply the mass fractal dimension. In the case of surface fractals, $A$ is proportional to the amount of the surfaces per unit volume and the surface fractal dimension $D_{s}$ can be calculated by $D_{s}=6-d[50]$.

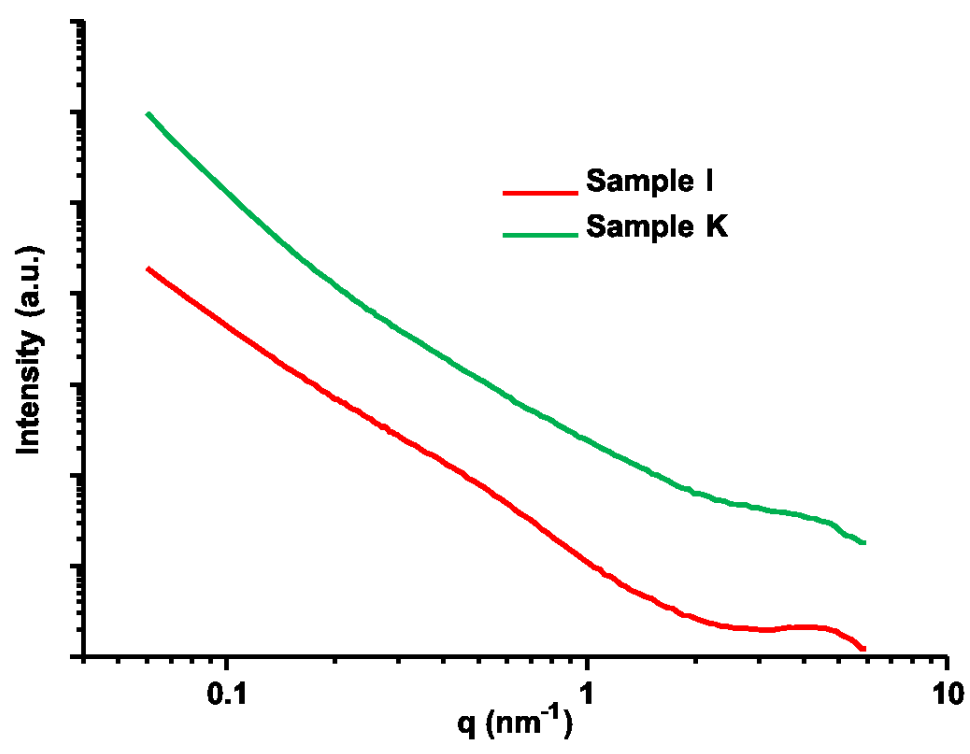

Figure 5: SAXS spectra of sample I and sample $K$. 
The values obtained for the exponent $d$ (Table 3 ) show that at this scale sample $K$ presents a relatively smooth fractal surface $\left(d=3.8 ; D_{s}=2.2\right)$, while sample $I$, shows a fractal dimension value $(d=2.8)$, indicative of a dense mass fractal.

At intermediate values of $q$ the scattering plots show a region that can be defined by a Guinier regime [53] followed by a power law, which can be modeled by the unified equation from Beaucage $[54,55]$

$$
I(q)=I_{o} \exp \left(-q^{2} R g^{2} / 3\right)+B\left(1 / q^{*}\right)^{\beta}+\text { background }
$$

where $I_{0}$ is the Guinier pre-factor, $B$ is the power-law pre-factor and $\beta$ its exponent. $R_{g}$ is the radius of gyration, related to the size of the largest heterogeneities, and $q^{*}$ is a value defined by

$$
q^{*}=q /\left[\operatorname{erf}\left(k q R_{g} / \sqrt{6}\right)\right]^{3}
$$

where $k$ is an empirical constant [55]. A least squares fitting of $I(q)$ was done and values of $R_{g}$ and $\beta$ were calculated (Table 3 ). Heterogeneities were assumed to have a spherical geometry and their diameter $D$ was calculated using the relation between the radius of gyration and the diameter of a homogeneous sphere:

$$
D=2(5 / 3)^{1 / 2} R_{g}
$$

From the results in Table 3 it can be observed that in both cases the diameters of heterogeneities are near $100 \AA$. Due to their size, these heterogeneities can be considered to be secondary silica particles with additives (calcium and titanium) on their surfaces as mentioned in the previous section. The $\beta$ exponents of the power law regime corresponding to those heterogeneities indicate that they can be described by mass fractals $(\beta<3)$. The value of $\beta$ obtained for the sample $K(\beta \approx 2)$ indicates that the growth of the mass fractal heterogeneities follows a reaction-limited cluster-cluster kinetic model, while in the case of sample I $(\beta \approx 3)$ a reaction-limited monomer-cluster model is more appropriate [56]. While the kinetic growth model presented by the former has also been observed for the $\mathrm{SiO}_{2}$ gel formation in an acid-catalyzed system [36,57], the later model is consistent with the authors' previous assumptions: (a) titanium alkoxide being less reactive (when compared to other transition metals 
alkoxides) interacts in a later stage of the process, making the location of titanium preferably on the surface of secondary particles, thus influencing the value of the fractal dimension; (b) Ti-O-Si bonds are not as stable in an acidic solution $[11,58,59]$ as Ti-O-Ti or Si-O-Si bonds, and hydrolyzed titanium atoms may act as "poisoned" growth sites on the secondary particles, generating a fractal structure similar to the poisoned-Eden model developed by Keefer [60]. The different preparation procedures $I$ and $K$ influence the obtained structures, inasmuch as titanium is not available in the case of $K$ to be present in the surface of the silica secondary particles.

For sample I the SAXS plot at high $q$ shows a well-defined peak corresponding to correlations between similar neighboring structures in a lattice, the height of the peak being related to the number of coordinated neighbors at a characteristic distance $a$ defined by $a=2 \pi / q$ [61]. This characteristic distance was found to be ca. $13 \AA$. The same was also obtained for the Guinier crossover of sample $K$ at high $q$. This value has been reported as the distance between metal-oxo domains embedded in the siloxane network [62-64], which is in agreement with the results of ${ }^{29} \mathrm{Si}$ MAS NMR, that indicated the maintenance of the full coordinated $Q^{4}$ signal in cross-polarization mode.

Table 3: values of power-law exponent $d$, radius of gyration $R_{g}$, the equivalent diameter $D$, power-low exponent $\beta$, all determined from the SAXS plots, and values of surface area and micropore area calculated from the nitrogen adsorption isotherms, for both type of samples.

\begin{tabular}{lcc}
\hline & \multicolumn{2}{c}{ Sample I Sample K } \\
\cline { 2 - 3 } power-law exponent $d$ & 2.8 & 3.8 \\
radius of gyration $R_{g}(\AA)$ & 38 & 47 \\
heterogeneities diameter $D(\AA)$ & 98 & 121 \\
power-law exponent $\beta$ & 2.9 & 1.9 \\
BET surface area $\left(\mathrm{m}^{2} \cdot \mathrm{g}^{-1}\right)$ & 36 & 273 \\
micropore surface area $\left(\mathrm{m}^{2} \cdot \mathrm{g}^{-1}\right)$ & n.d. & 23 \\
\hline
\end{tabular}




\subsection{Surface area determination by nitrogen adsorption}

Specific surface areas of samples were obtained from the nitrogen adsorptiondesorption isotherms (Figure 6), using the Brunauer-Emmet-Teller (BET) method [26] and micropore surface areas were obtained using the t-plot method [27]. The results are shown in Table 3. Both $I$ and $K$ samples are characterized by type II isotherms which are usually related to macroporous materials (pore diameter $>50 \mathrm{~nm}$ ) with a type $\mathrm{H} 3$ hysteresis loop, which extends to low pressures, revealing the existence of some mesopores $(2 \mathrm{~nm}<$ pore diameter < $50 \mathrm{~nm}$ ). This type of low pressure hysteresis is associated with the swelling of a non-rigid porous structure [26].

Procedure $K$ produced a sample with a surface area almost seven times higher than the one presented by sample $I$. This result is consistent with the difference between the growth kinetics of the two samples, already observed in the previous section, noting that the reaction limited cluster-cluster kinetic model is usually associated with high specific surface area samples [36].

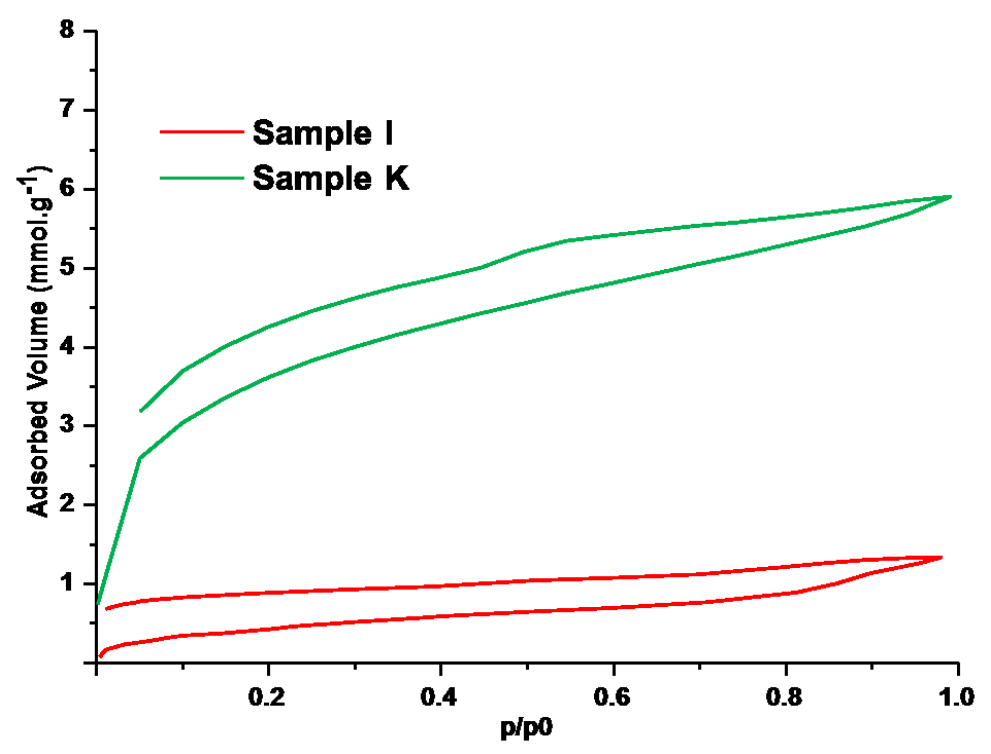

Figure 6: Nitrogen adsorption-desorption isotherms for both samples. 


\subsection{Surface topography analysis}

Surface topography of cut discs of $I$ and $K$ samples was evaluated using a 3D optical variation system (Figure 7). Five parameters that are commonly used on cell adhesion and proliferation studies were measured: arithmetic mean deviation of the surface $\left(R_{a}\right)$, root-mean-square deviation of the surface $\left(R_{q}\right)$, maximum height of summits $\left(R_{p}\right)$, maximum depth of valleys $\left(R_{v}\right)$, and total height of the surface $\left(R_{t}\right)$. The surface fractal dimension $\left(D_{f}\right)$ and the developed area ratio $\left(S_{d r}\right)$ were also calculated and the results are presented in Table 4.

It is clear that the surface morphology of the two samples is completely different, sample $I$ being rougher than $K$. Although in totally different length scales, it is interesting to compare these surface fractal values $D_{f}$ (Table 4 ) with the values of the power-law exponent $d$ observed in the SAXS tests (Table 3) and see how these structures evolve from the nano scale to the macroscopic scale.

Table 4: Surface topography related values and contact angle values of samples discs (standard deviation values in brackets).

\begin{tabular}{lcc}
\hline & Sample I & Sample K \\
\cline { 2 - 3 } $\mathrm{R}_{\mathrm{a}}(\mu \mathrm{m})$ & $35.58(0.08)$ & $0.76(0.00)$ \\
$\mathrm{R}_{\mathrm{q}}(\mu \mathrm{m})$ & $49.98(0.12)$ & $0.96(0.00)$ \\
$\mathrm{R}_{\mathrm{p}}(\mu \mathrm{m})$ & $116.68(0.02)$ & $3.77(0.00)$ \\
$\mathrm{R}_{\mathrm{v}}(\mu \mathrm{m})$ & $476.36(0.10)$ & $3.57(0.00)$ \\
$\mathrm{R}_{\mathrm{t}}(\mu \mathrm{m})$ & $593.04(0.02)$ & $7.34(0.00)$ \\
$\mathrm{D}_{\mathrm{f}}$ & 2.3 & 2.01
\end{tabular}




$\begin{array}{lcc}\mathrm{S}_{\mathrm{dr}}(\%) & 2782.4 & 3.64 \\ \theta_{\mathrm{m}}\left({ }^{\circ}\right) & 127.2(3.8) & 150.6(2.5) \\ \theta_{\mathrm{Y}}\left({ }^{\circ}\right) & 91.2 & 91<\theta_{\mathrm{Y}}<110\end{array}$

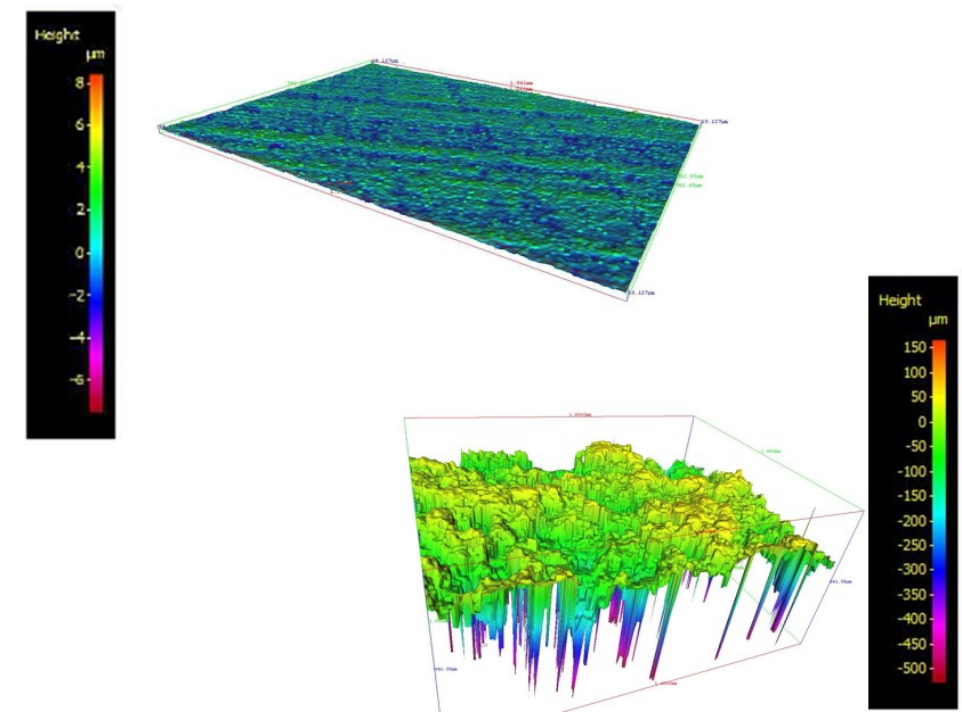

Figure 7: 3D topography of sample K (top) and sample I (bottom) discs.

\subsection{Static contact angle}

Static contact angle $\theta_{m}$ values were measured using the sessile drop method and results are depicted in Table 4 for samples $I$ and $K$. For both samples their surfaces are hydrophobic $\left(\theta_{m}>90^{\circ}\right)$ (Figure 8 ).

Values were measured from the video frames obtained by a CCD camera after the stabilization of the drop. It was observed that in the case of sample I, after some time, the drop was absorbed by the material. Applying Wenzel equation (Eq. 1) the Young contact angle $\theta_{Y}$ was found to be $91.2^{\circ}$. This result is in agreement with the ones reported in the literature [52], considering the amount 
of PDMS used in the present work in the preparation of the samples and the values of contact angle referred for PDMS itself, $100^{\circ}<\theta_{Y}<110^{\circ}[52,65]$.

In contrast, no absorption effect was detected in the case of sample $\mathrm{K}$, indicating a non-filling regime [65]. In fact, it was necessary to increase the drop volume from $2 \mu \mathrm{L}$ to $10 \mu \mathrm{L}$ in order to have a static situation for taking the measurements. Even so, the material surface showed a roll-off characteristic (low adhesive force between the liquid drop and the solid substrate) recalling a non-wetting regime known as a Cassie-Baxter state [28]. In this state the liquid cannot penetrate into the surface texture due to entrapped air which results in a decrease of the effective contact area between the surface and the drop and in the adhesive force. According to the literature this regime designated by super hydrophobic is attained due to the surface morphology as demonstrated by Jopp et al. for PDMS [65]. In the present case, the measured value $\theta_{m}$ is $150.6^{\circ}$, is well above the values known for PDMS flat surfaces. Assuming that sample $K$ surface energy is higher than a pure PDMS one, due to the presence of hydrophilic oxide domains (physisorbed water was detected as shown by FT-IR and ${ }^{1} \mathrm{H}$ NMR MAS spectra results), it is possible to use the Cassie-Baxter equation (Eq. 3) to calculate the fraction of the sample $K$ which is effectively in contact with water. For sample $K \theta_{Y}$ varies between $91^{\circ}$ and $110^{\circ}$, the upper limit being the value for PDMS itself and the lower limit the value observed for sample $I$. The fraction of area in contact with the liquid $\varphi_{\mathrm{s}}$ was calculated to lie in the interval $0.13<\varphi_{\mathrm{s}}<0.20$. This is slightly higher than the fraction of the surface which consists of hills above the core material (calculated from the 3D surface topography analysis), which for sample $K$ is 0.10 .

These results agree with the assumption that longer PDMS chains link silica domains, creating a hydrophobic surface as confirmed by NMR and SAXS measurements, also in agreement with a structural model proposed by Zhang et al. [52,51] where PDMS chains act as bridges between the surface of silica nano particles. 


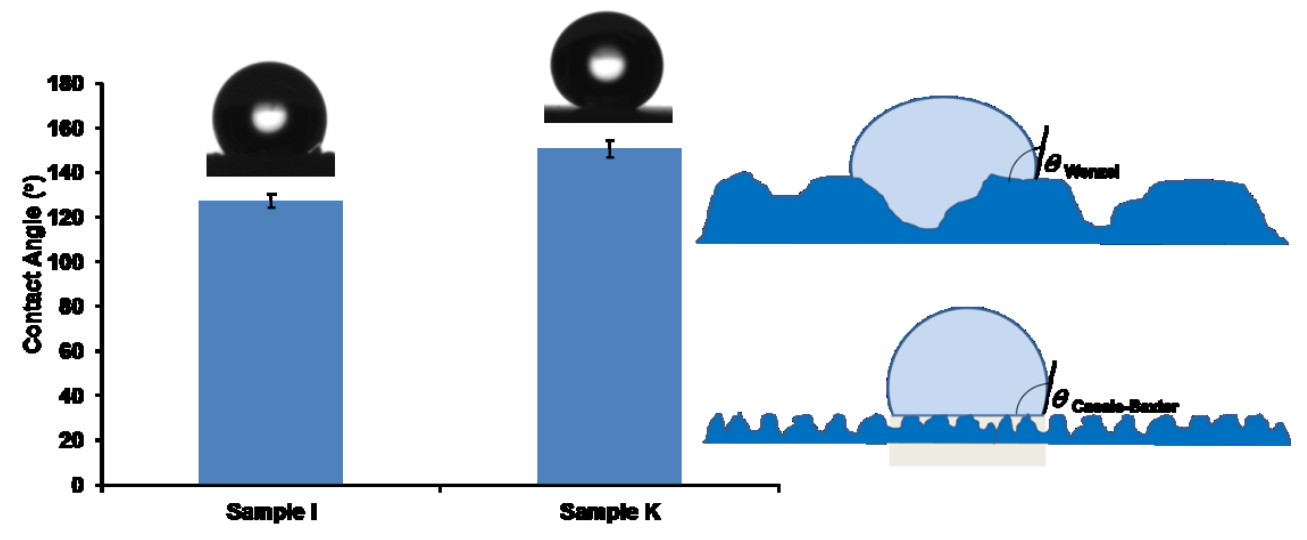

Figure 8: Values measured for the static contact angle of cut disc surfaces for sample I (Wenzel regime) and sample K (Cassie-Baxter regime).

\subsection{In vitro evaluation}

\subsubsection{Bioactivity studies}

The surfaces of cut discs from both samples $I$ and $K$, were observed by SEM and analysed by EDS after immersing in SBF for 3, 7 and 14 days. SEM images and the corresponding EDS spectra obtained before and after immersion (3 days) are shown in Figure 9 and 10, respectively. The presence of surface precipitates is evident after soaking in SBF for 3 days and the EDS spectra suggest calcium phosphate aggregates, confirmed as apatite-like by grazing incidence X-ray diffraction (GIXRD) analysis (Figure 10) [66]. The EDS spectra also show the presence of $\mathrm{Cl}$ probably due to the $\mathrm{HCl}$ used in the samples preparation. 


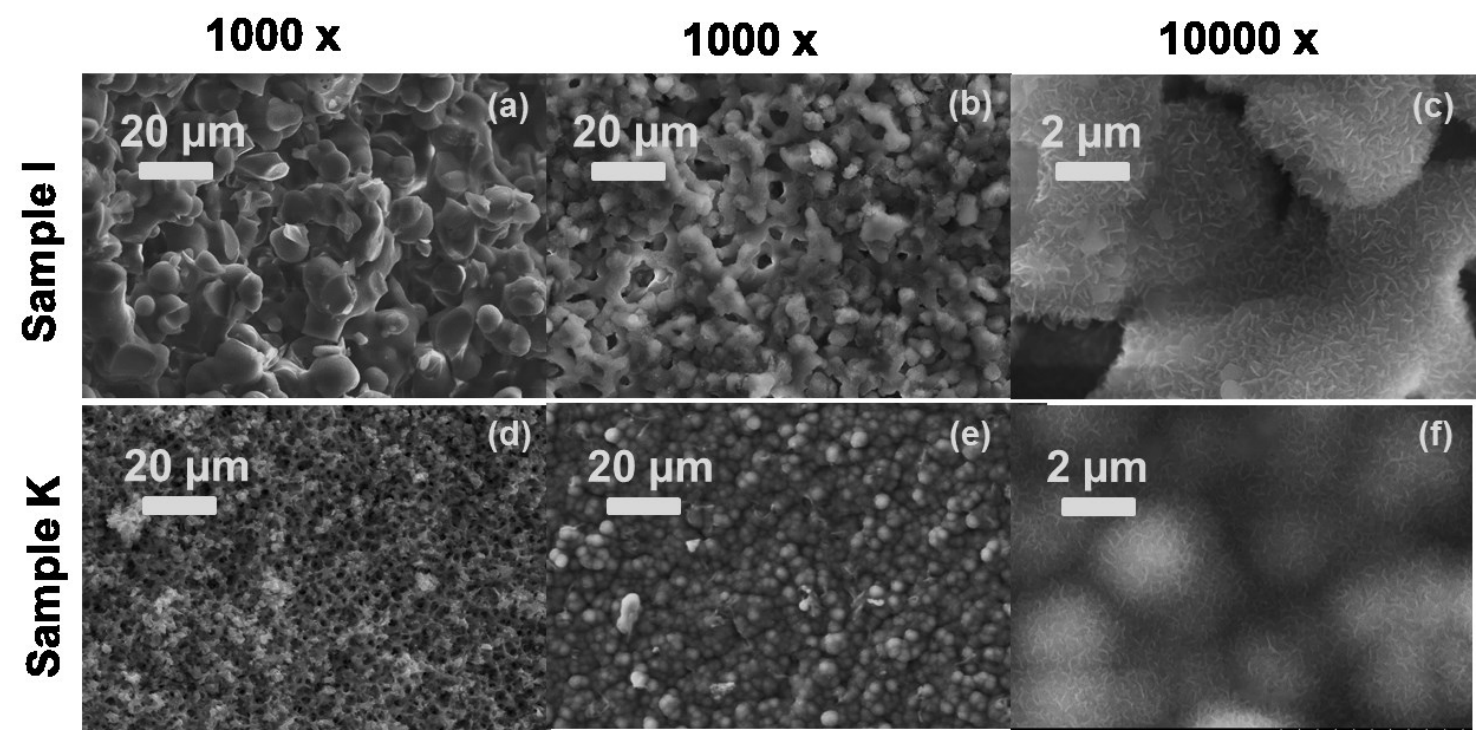

Figure 9: SEM images for before ( $a$ and $d$ ) and after ( $b, c$, e and f) immersion in SBF for 3 days. Photos from first and second column: $1000 \times$ magnification. Photos from third column: $10.000 \times$ magnification.

ICP results in Figure 11 show the $\mathrm{Ca}$ and $\mathrm{P}$ concentration in the supernatant liquids in relation to their initial concentrations in SBF. This results show that while in the sample $I$ the release of calcium is gradual, in sample $K$ there is a fast initial release (day 3 ), followed by deposition and a balance dissolution/deposition on days 7 and 14 . In sample $K$, the initial release of $\mathrm{Ca}$ appears to be associated with a significant deposition of phosphates (a marked decrease of $\mathrm{P}$ concentration on day 3 ), followed by dissolution (increase of $\mathrm{P}$ on days 7 and 14). As in the case of calcium, the concentration of phosphorous on days 7 and 14 are similar which also suggests the existence of a dynamic equilibrium between events dissolution/deposition or the displacement of the apatite layer. This result suggest that the formation of the apatite layer is faster in sample $K$, but their stability is smaller, as observed in SEM/EDS (Figure 9), being the kinetics of these events slower in sample $I$.

This fast release of calcium observed for sample $K$ is in agreement with its higher surface area. Also, from the observation of ${ }^{1} \mathrm{H}$ MAS NMR spectra (Figure 3 ), and as explained in section 3.2, sample $K$ presents a higher amount of physisorbed water than sample $I$. As reported by other authors for bioglass compositions $[43,44]$ this difference in the amount of physisorbed water are 
related to the $\mathrm{Ca}^{2+}$ concentration in the surface. Thus, one can conclude that sample $K$ presents a higher concentration of calcium ions at its surface when compared to sample $I$, in agreement with the ICP results.

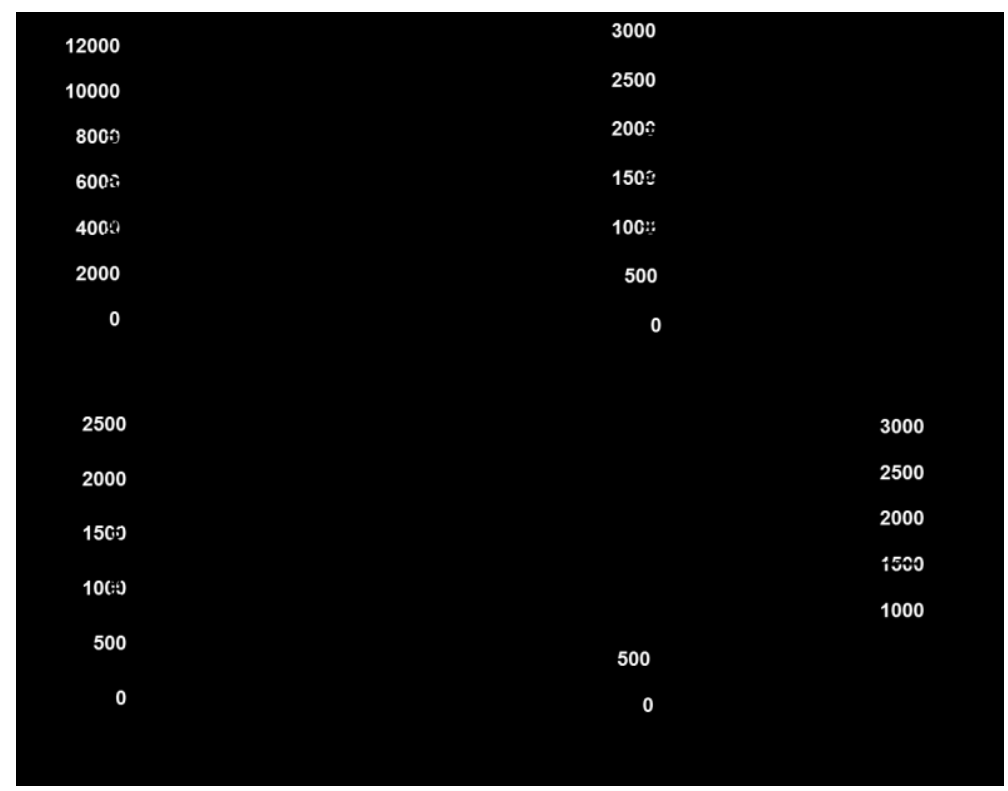

Figure 10: EDS spectra (left) obtained for discs surface after immersion in SBF for 3 days. GIXRD spectra (right) of discs surface before (0 day) and after immersion in SBF (3 and 7 days). •Apatite related peaks [66].

Despite the overall highly hydrophobic nature of the surfaces, a surface layer of apatite precipitated in both samples after 3 days on SBF, revealing that hydrophilic domains are present. This observation agrees with the results from SAXS and NMR analysis which show the existence of nano domains with a mass fractal structure, probably silica secondary particles with some calcium in their surfaces. The existence of a heterogeneous surface, with hydrophilic and hydrophobic domains, in both I and $\mathrm{K}$ explains why the development of apatitelike precipitates is observed despite the high value of contact angle. Using the model proposed by Checco et al. [67] who explore the change in contact angle with decreasing drop size (tiny drops appear preferentially on the most wettable spots, acting as initiator sites for the condensation) it is possible to imagine the hydrophilic domains acting as nucleation spots for the apatite-like precipitates. As these precipitates grow they reach the hydrophobic domains where they spread even without the contribution of any type of bonding. 
It was also observed by SEM and GIXRD (Figure 10) that no precipitated layer is present in the surfaces of sample $\mathrm{K}$ discs after soaked in SBF for 7 and 14 days. Probably, after being precipitated in the first days, the apatite-like layer detaches due to the super hydrophobic character of the surface, and dissolves in the SBF as proposed above.
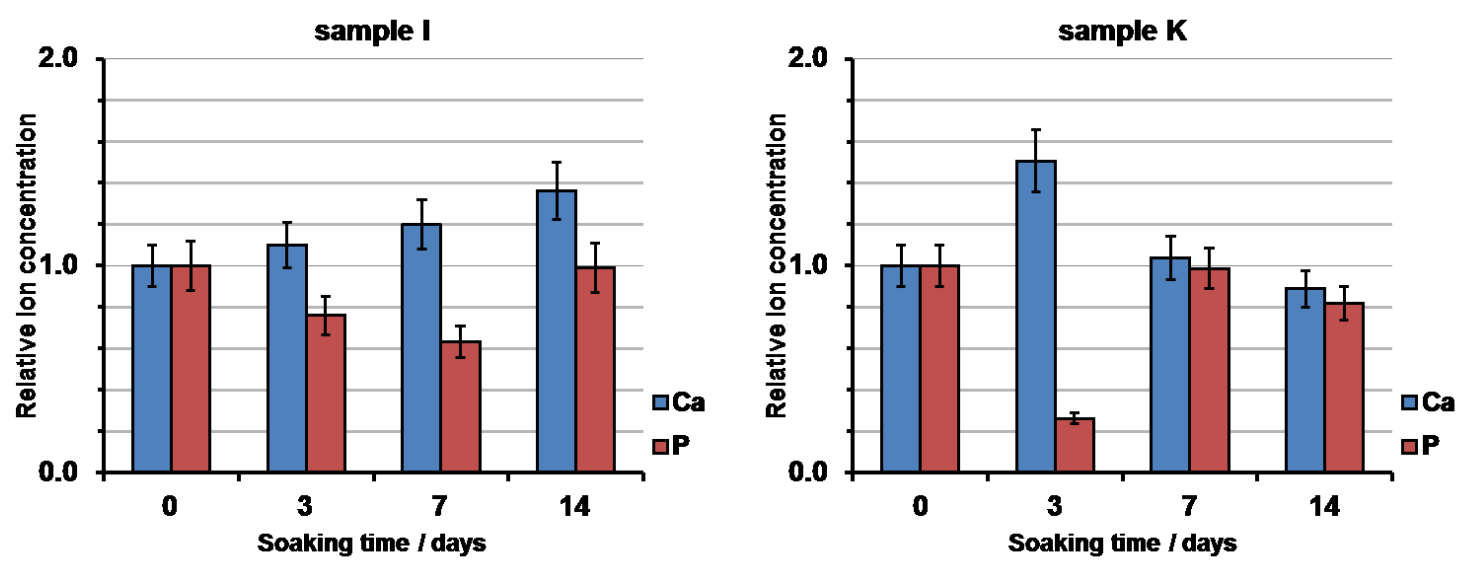

Figure 11: $\mathrm{Ca}$ and $\mathrm{P}$ relative ion concentration of supernatant liquids obtained after immersion in SBF.

\subsubsection{Biocompatibility studies}

Samples I and $K$ were seeded with MG63 osteoblastic cells, cultured for 8 days, and evaluated for cell proliferation, ALP activity, cell morphology and F-actin cytoskeleton staining.

Cell proliferation, measured by the DNA content increased throughout the culture time in both materials. Values were lower on samples $K$, particularly for longer culture times, $\sim 30 \%$ at day 8 . ALP activity followed a similar pattern, with a reduction of $\sim 25 \%$ at day 8 . Results are shown in Figure 12 . 

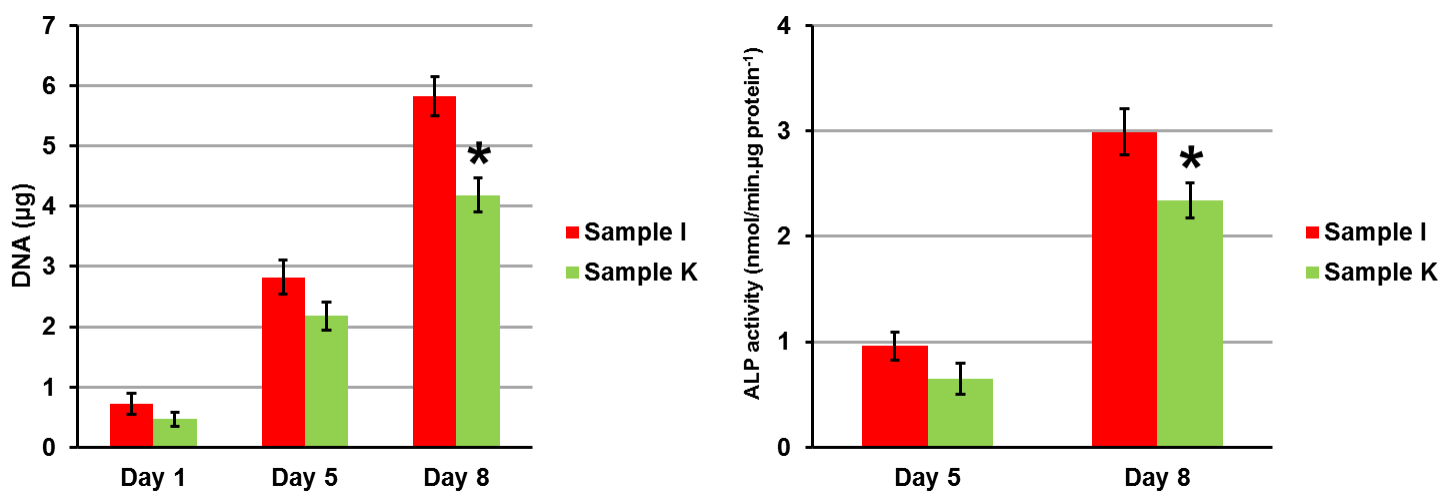

Figure 12: Cell proliferation (left) and alkaline phosphatase activity (right) for samples I and K. * statiscally different from Sample I.

CLSM images of the colonized materials, labelled for the F-actin cytoskeleton, are presented in Figure 13a. Cell adhesion occurred on both materials, as shown on day 1 images, followed by an active process of proliferation, as noted at days 5 and 8 , and in line with the DNA results. However, evident differences on the cell morphology and pattern of cell growth were observed. On samples $I$, cells presented a round morphology at day 1, but the nucleus was already visible and the cytoplasm expansion was in progress. During the growth phase, cells were randomly distributed over the surface, showing an oval/elongated morphology with variable cell spreading. Additionally, images strongly suggested that cells were present at different levels on the material surface, most probably adapting/filling the rough topography of this material. Instead, on samples $K$, at day 1 , a better definition of the nucleus and a higher cell spreading were noted. Afterwards, cells formed well-defined clusters, regardless the low density over the material's surface; also, within these clusters, cells were well-spread, flattened and elongated, with visible and prominent nucleus, presenting a relatively identical morphology and size. This behavior is suggestive of cells growing on a flat surface, which is expected considering the very low surface roughness of samples $K$ compared to that of samples I. SEM images, shown at day 5, Figure $7.13 \mathrm{~b}$, corroborate CLSM observations. Samples / display cells with a globular appearance and different sizes growing towards the cavities of the rough topography, whereas on samples $K$ cells appeared well spread and flat. 
Surface features of samples $I$ and $K$, as to the roughness/topography and the hydrophobic wetting/non-wetting behavior, have a significant influence on the cell response observed over the two materials.

Sample $I$, with a rough surface, presents a filling wetting behavior, as explained before. Upon cell seeding, the culture medium would follow a similar trend, filling the rough topography with its summits and valleys, allowing for the adsorption of cell-adhesion mediating proteins in the all irregular surface. On wettable surfaces these adhesion molecules appear to be adsorbed in a flexible form, being reorganized by the cells to provide privileged access for cell adhesion receptors, leading to a customized cell adhesion and spreading process, a phase that has a crucial role on cell proliferation and differentiation [68]. Cell colonization appears identical in the whole surface of sample $I$, as made evident by the CLSM and SEM images, showing that cells are able to adhere and grow towards and inside the surface irregularities, suggesting that all the rough surface is available for the cell/material interactions, which is expected on surfaces following the Wenzel regime [69].

Comparatively, sample $K$ presents a very low surface roughness, and its hydrophobic surface exhibits a non-filling wetting behavior. Accordingly, the culture medium containing the cell suspension does not penetrate the surface texture, and adsorption of adhesion molecules and cells occur only onto the peaks of the low surface roughness of this material, greatly reducing the available contact area for biological interactions, in accordance with that described for the Cassie-Baxter regime [69]. Thus, once cell adhesion occurs on the hydrophilic domains of sample $K$, cells would spread over the tiny surface summits, acquiring a flattened and elongated morphology, resembling the one occurring on a flat surface. Additionally, cells tend to proliferate in clusters of stacked cells, suggesting that they encounter a more favorable microenvironment for adhesion and the subsequent proliferation stage in the multi-layer cluster organization, rather than establishing contact adhesions with the highly hydrophobic materials' surface. However, as it was observed with the formation of the apatite layer, cell clusters grew with the culture time and, eventually, the whole surface is colonized. Figure 14 present a schematic 
representation of these cell/materials surface interactions for both sample $I$ and sample $K$.

(a)
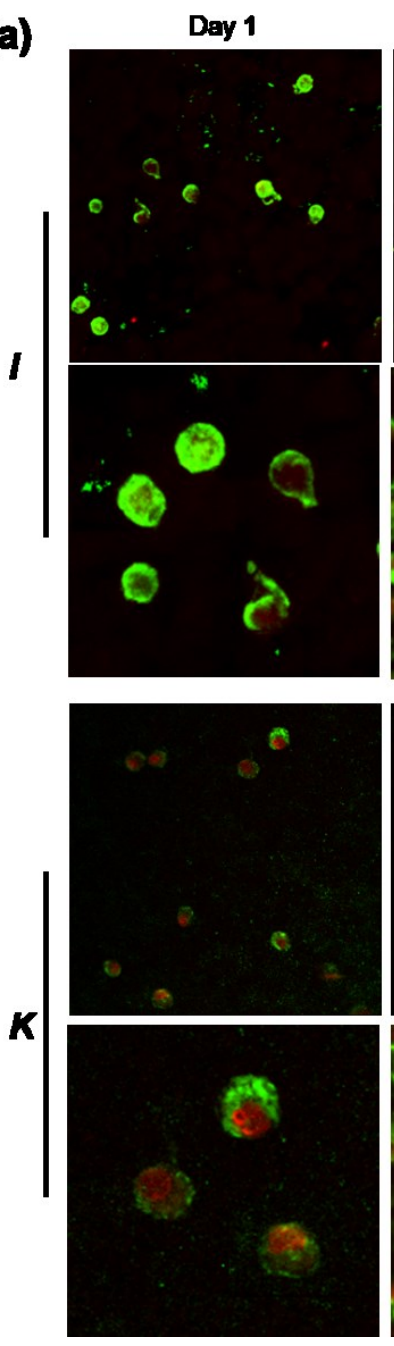

Day 5
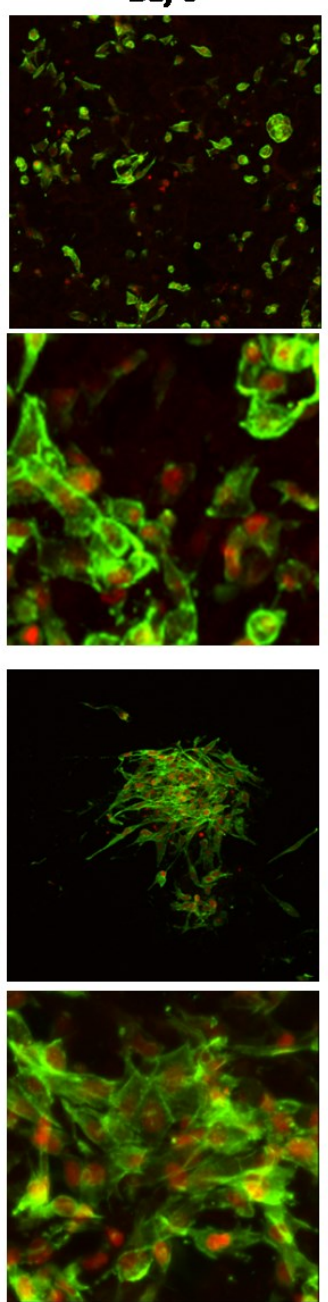

Day 8

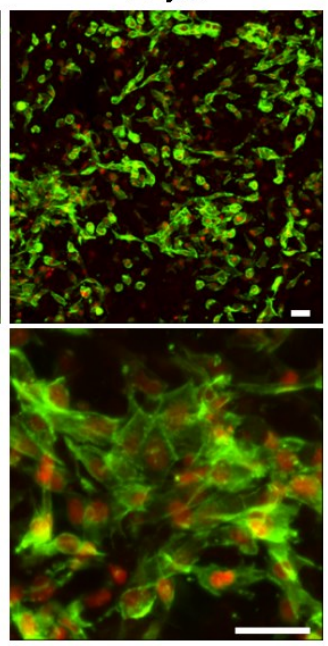

(b)
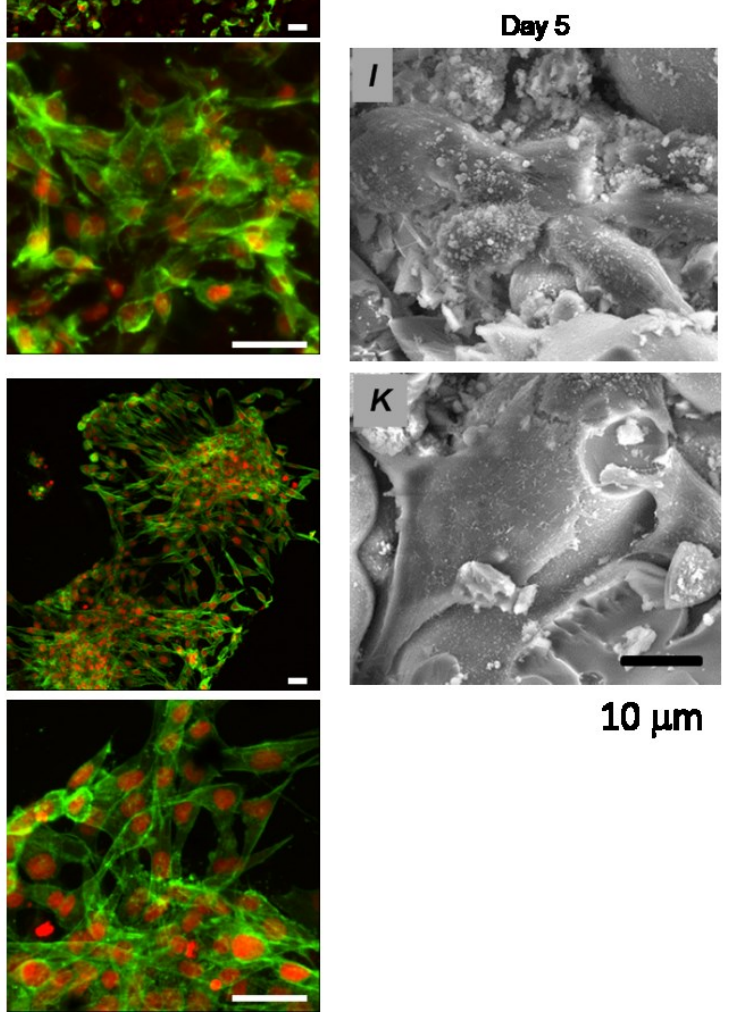

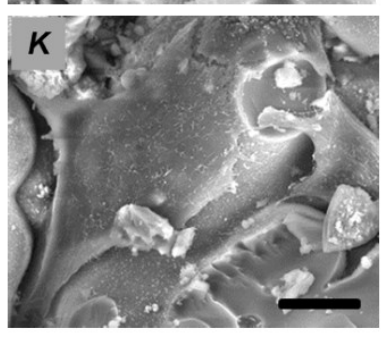

$10 \mu \mathrm{m}$

Figure 13: (a) Confocal Laser Scanning Microscopy (CLSM) and (b) SEM observation of the colonized materials. Scale bar on confocal images corresponds to $100 \mu \mathrm{m}$.

As mentioned above, differences on the cell response over samples $I$ and $K$ were observed early on the cell/material interactions, namely regarding the degree of cell spreading, resulting in different morphologies. Cell spreading is a determinant event on the subsequent cell behavior, as it stimulates cell proliferation by biochemical and mechanical pathways. Binding of specific proteins in the material surface with the cell-adhesion receptors is linked to a 
complex cascade of intracellular signaling pathways which activates cell cycle progression hastening cell proliferation [70]. Mechanical pathways also play a relevant role. F-actin fibers anchor to the structural components of the adhesion sites, but they are also associated with the membranes of the cellular organelles, including the nucleus. The increasing tension of the F-actin cytoskeleton during cell spreading can stimulate cell proliferation by nuclear expansion that activates the replication machinery by several mechanisms [71]. However, the dependence of cell spreading and cell proliferation is not linear and it occurs only to a certain degree [70]. Besides, material surface properties such as roughness, topography and wettability are known to greatly influence the cell spreading/proliferation dependency, and an increased cell spreading does not correlate with a higher cell proliferation in a variety of contexts [68], as might happen in samples $/$ and $K$.

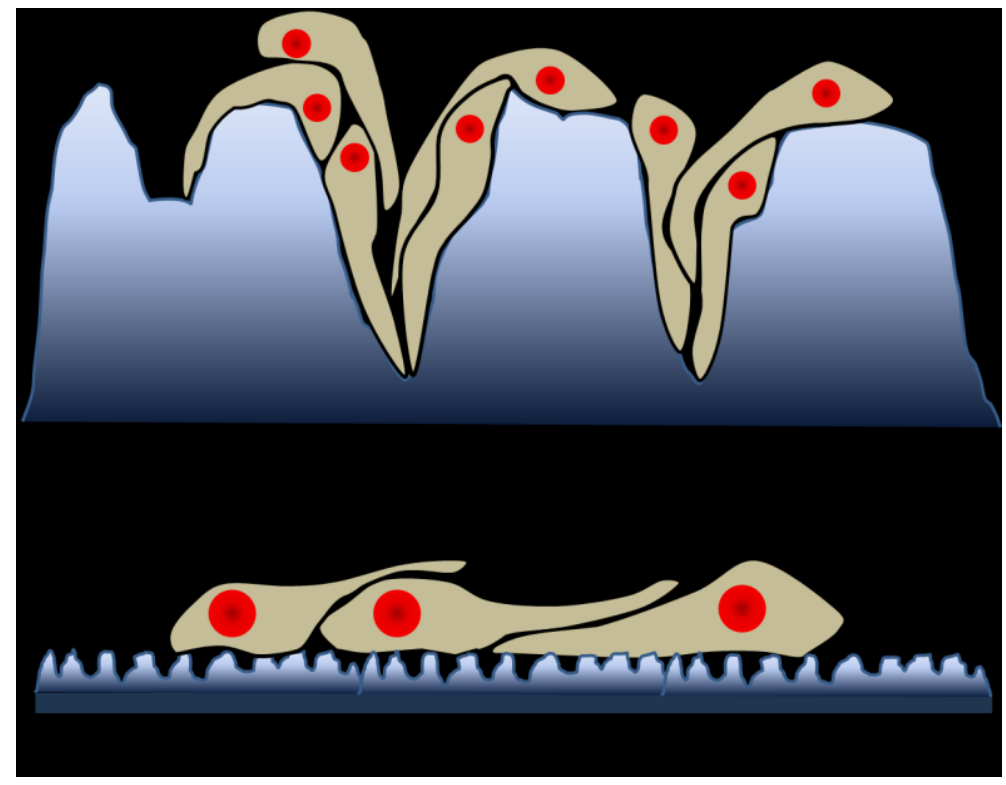

Figure 14: Schematic representation of cell/materials surface interactions.

Anchorage-dependent cells are inherently sensitive to the surface microtopography. MG63 cells have sizes usually in the range 20 to $60 \mu \mathrm{m}$ and, apparently, were able to attach and to grow towards and inside the cavities of sample $I$, as it was expected considering the wettability of this material. As seen 
in CLSM and SEM images, the surface topography affected the cell spreading area and morphology, reflected by the observed variability in these parameters, in order to conciliate with the irregular surface features. Microroughness is a controversial factor affecting cell behavior and the involved mechanisms are not easily clarified, due to the great variability of protocols and concomitant factors that also affect cell response. Nevertheless, a variety of studies addressing different materials, report positive effects on cell adhesion, growth and differentiation, within certain range values, dependent on other surface parameters [72]. A relevant issue appears to be related with a higher strength of cell adhesion in this type of topography, which has a decisive role on the subsequent cell proliferation and differentiation, contributing to the establishment of stable cell layers interacting with the material surface. In material $I$, the eventual positive effects of the topography might also act synergistically with the wettability behavior, due to the possibility of increased protein/cell/material surface interactions. Instead, sample $K$, with a comparatively lower surface roughness, higher hydrophobicity and non-filling wetting behavior substantiate a poor cell adhesion and proliferation, according to that reported in this context [68]. However, in material $K$, this is apparently compensated by the presence of hydrophilic domains by keeping the adsorbed protein adhesion molecules in an appropriate conformation for binding with the cell adhesion receptors [73], rendering this surface also suitable for the adhesion and proliferation of the osteoblastic cells. However, the different combination of surface roughness/wetting regime of samples $I$ and $K$ might explain, at least partially, the distinct cell growth pattern observed in the two samples, reflected by, respectively, an homogeneous and a clustering-type cell colonization. Additionally, the lower effective surface area of sample $K$ might contribute to the lower DNA values observed in this material, especially noticed at longer incubation times, which allowed for a greater extent of colonization on the high effective area of sample I. Additionally, activity of ALP, an early markers of osteoblastic differentiation with a key role in the onset of the matrix mineralization, was also higher on sample $I$. This suggests that the surface features of this material seem more favorable for osteogenic differentiation, which appears very likely considering the roughness /wetting profile of the two samples. 


\section{Conclusions}

Based on authors' prior knowledge about the role of titanium on the sol-gel processing of $\mathrm{PMDS}-\mathrm{SiO}_{2}$ based hybrids, two different $\mathrm{PDMS}-\mathrm{SiO}_{2}-\mathrm{TiO}_{2}-\mathrm{CaO}$ monolithic materials were prepared following different sol-gel routes, but using the same base composition and calcium acetate as calcium source. The two different routes produced monolithic materials with different structures, microstructures, and surface wettability, being both highly hydrophobic (water contact angles of $127.2^{\circ}$ and $150.6^{\circ}$ ) and presenting different filling regimes (Wenzel and Cassie-Baxter, respectively) due to different surface topographies. Even though, they have demonstrated to be cytocompatible when tested with human osteoblastic cells, against the accepted idea that high-hydrophobic surfaces are not suitable for cell adhesion and proliferation. This capability is assumed to be supported by the existence of hydrophilic silica domains containing calcium at the nanoscale, where water molecules are physisorbed and where the proteins adhere, starting the biological interaction with the surface.

The material with a rougher surface, that presented a Wenzel wetting regime, possess a synergetic combination of surface roughness/wettability that appeared to be more favorable for osteogenic differentiation.

The present study showed that the knowledge of the structural and microstructural features, developed in the sol-gel process can be strategically used to make the tailoring of inorganic-organic hybrid materials with applications in tissue regeneration or in other emerging research areas.

\section{Acknowledgments}

This work was financed by the JECS Trust (Contract 201467), FEDER funds (Program COMPETE) and by FCT funds, by the grant SFRH/BD/72074/2010 and also developed in the scope of the project CICECO-Aveiro Institute of Materials (Ref. FCT UID/CTM /50011/2013), financed by national funds through 
the FCT/MEC and when applicable co-financed by FEDER under the PT2020 Partnership Agreement.

References

[1] K. Tsuru, C. Ohtsuki, A. Osaka, T. Iwamoto, J.D. Mackenzie, Bioactivity of sol-gel derived organically modified silicates .1. In vitro examination, J. Mater. Sci. Med. 8 (1997) 157-161.

[2] K. Tsuru, Y. Aburatani, T. Yabuta, S. Hayakawa, C. Ohtsuki, A. Osaka, Synthesis and in vitro behavior of organically modified silicate containing Ca ions, J. Sol-Gel Sci. Technol. 21 (2001) 89-96.

[3] M. Kamitakahara, M. Kawashita, N. Miyata, T. Kokubo, T. Nakamura, Bioactivity and mechanical properties of polydimethylsiloxane (PDMS)$\mathrm{CaO}-\mathrm{SiO}_{2}$ hybrids with different PDMS contents, J. Sol-Gel Sci. Technol. 21 (2001) 75-81.

[4] M. Kamitakahara, M. Kawashita, N. Miyata, T. Kokubo, T. Nakamura, Bioactivity and mechanical properties of polydimethylsiloxane (PDMS)$\mathrm{CaO}-\mathrm{SiO}_{2}$ hybrids with different calcium contents, J. Mater. Sci. Med. 13 (2002) 1015-1020.

[5] M. Vallet-Regi, A.J. Salinas, J. Ramirez-Castellanos, J.M. GonzalezCalbet, Nanostructure of bioactive sol-gel glasses and organic anorganic hybrids, Chem. Mater. 17 (2005) 1874-1879.

[6] A.J. Salinas, J.M. Merino, F. Babonneau, F.J. Gil, M. Vallet-Regi, Microstructure and macroscopic properties of bioactive $\mathrm{CaO}-\mathrm{SiO}_{2}$-PDMS hybrids, J. Biomed. Mater. Res. Part B-Applied Biomater. 81B (2007) 274-282.

[7] M. Manzano, A.J. Salinas, F.J. Gil, M. Vallet-Regi, Mechanical properties of organically modified silicates for bone regeneration, J. Mater. Sci. Med. 20 (2009) 1795-1801.

[8] J.R. Jones, Review of bioactive glass: From Hench to hybrids, Acta Biomater. 9 (2013) 4457-4486.

[9] Q. Chen, F. Miyaji, T. Kokubo, T. Nakamura, Apatite formation on PDMSmodified $\mathrm{CaO}-\mathrm{SiO}_{2}-\mathrm{TiO}_{2}$ hybrids prepared by sol-gel process, Biomaterials. 20 (1999) 1127-1132.

[10] P. Li, C. Ohtsuki, T. Kokubo, K. Nakanishi, N. Soga, K. de Groot, The role of hydrated silica, titania, and alumina in inducing apatite on implants., J. Biomed. Mater. Res. 28 (1994) 7-15. 
[11] C. Sanchez, F. Ribot, Design of Hybrid Organic-Inorganic Materials Synthesized Via Sol-Gel Chemistry, New J. Chem. 18 (1994) 1007-1047.

[12] J.C. Almeida, A. Wacha, A. Bóta, L. Almásy, M.H. Vaz Fernandes, F.M.A. Margaça, et al., $\mathrm{PDMS}-\mathrm{SiO}_{2}$ hybrid materials - a new insight into the role of $\mathrm{Ti}$ and $\mathrm{Zr}$ as additives, Polymer 72 (2015) 40-51.

[13] G. Ellis, I. Adatia, M. Yazdanpanah, S.K. Makela, Nitrite and nitrate analyses: A clinical biochemistry perspective, Clin. Biochem. 31 (1998) 195-220.

[14] C.C. Hunault, A.C. Lambers, T.T. Mensinga, J.W. van Isselt, H.P.F. Koppeschaar, J. Meulenbelt, Effects of sub-chronic nitrate exposure on the thyroidal function in humans, Toxicol. Lett. 175 (2007) 64-70.

[15] J.C. Almeida, A.G.B. Castro, J.J.H. Lancastre, I.M. Miranda Salvado, F.M.A. Margaça, M.H.V. Fernandes, et al., Structural characterization of PDMS-TEOS-CaO- $\mathrm{TiO}_{2}$ hybrid materials obtained by sol-gel, Mater. Chem. Phys. 143 (2014) 557-563.

[16] A.G.B. Castro, J.C. Almeida, I.M.M. Salvado, F.M.A. Margaca, M.H. V Fernandes, A novel hybrid material with calcium and strontium release capability, Mater. Lett. 88 (2012) 12-15.

[17] J. Carlos Almeida, A.G.B. Castro, I.M. Miranda Salvado, F.M.A. Margaça, M.H. Vaz Fernandes, A new approach to the preparation of $\mathrm{PDMS}-\mathrm{SiO}_{2}$ based hybrids - A structural study, Mater. Lett. 128 (2014) 105-109.

[18] T. Kokubo, H. Takadama, How useful is SBF in predicting in vivo bone bioactivity?, Biomaterials. 27 (2006) 2907-2915.

[19] J.C. Almeida, J. Lancastre, M.H. Vaz Fernandes, F.M.A. Margaça, L. Ferreira, I.M. Miranda Salvado, Evaluating structural and microstructural changes of $\mathrm{PDMS}-\mathrm{SiO}_{2}$ hybrid materials after sterilization by gamma irradiation., Mater. Sci. Eng. C. Mater. Biol. Appl. 48 (2015) 354-8.

[20] D. Massiot, F. Fayon, M. Capron, I. King, S. Le Calve, B. Alonso, et al., Modelling one- and two-dimensional solid-state NMR spectra, Magn. Reson. Chem. 40 (2002) 70-76.

[21] F. Babonneau, Hybrid siloxane-oxide materials via sol-gel processing: Structural characterization, Polyhedron. 13 (1994) 1123-1130.

[22] R.H. Glaser, G.L. Wilkes, C.E. Bronnimann, Solid-State Si-29 NMR of Teos-Based Multifunctional Sol-Gel Materials, J. Non. Cryst. Solids. 113 (1989) 73-87.

[23] T. Iwamoto, K. Morita, J.D. Mackenzie, Liquid-State Si-29 NMR-Study on the Sol-Gel Reaction-Mechanisms of Ormosils, J. Non. Cryst. Solids. 159 (1993) 65-72. 
[24] I. Hasegawa, M. Ishida, S. Motojima, S. Satokawa, Organic-Silica Materials Consisting of the Double 4-Ring Silicate Structure as a BuildingBlock, Better Ceram. Through Chem. Vi. 346 (1994) 163-168.

[25] A. Wacha, Z. Varga, A. Bóta, CREDO: a new general-purpose laboratory instrument for small-angle X-ray scattering, J. Appl. Crystallogr. 47 (2014) $1749-1754$.

[26] K.S.W. Sing, Reporting physisorption data for gas/solid systems with special reference to the determination of surface area and porosity (Recommendations 1984), Pure Appl. Chem. 57 (1985) 603-619.

[27] S. Lowell, J.E. Shields, M.A. Thomas, M. Thommes, Characterization of Porous Solids and Powders: Surface Area, Pore Size and Density, Springer Netherlands, Dordrecht, 2004.

[28] A. Lafuma, D. Quere, Superhydrophobic states, Nat Mater. 2 (2003) 457460.

[29] J.I. Rosales-Leal, M.A. Rodríguez-Valverde, G. Mazzaglia, P.J. RamónTorregrosa, L. Díaz-Rodríguez, O. García-Martínez, et al., Effect of roughness, wettability and morphology of engineered titanium surfaces on osteoblast-like cell adhesion, Colloids Surfaces A Physicochem. Eng. Asp. 365 (2010) 222-229.

[30] H. Nguyen, D.A.F. Morgan, M.R. Forwood, Sterilization of allograft bone: is $25 \mathrm{kGy}$ the gold standard for gamma irradiation?, Cell Tissue Bank. 8 (2007) 81-91.

[31] IAEA, Trends in Radiation Sterilization of Health Care Products, Vienna, 2008.

[32] F. Babonneau, K. Thorne, J.D. Mackenzie, Dimethyldiethoxysilane/tetraethoxysilane copolymers: precursors for the silicon-carbon-oxygen system, Chem. Mater. 1 (1989) 554-558.

[33] L. Tellez, J. Rubio, F. Rubio, E. Morales, J.L. Oteo, FT-IR study of the hydrolysis and polymerization of tetraethyl orthosilicate and polydimethyl siloxane in the presence of tetrabutyl orthotitanate, Spectrosc. Lett. 37 (2004) 11-31.

[34] F. Rubio, J. Rubio, J.L. Oteo, A FT-IR study of the hydrolysis of tetraethylorthosilicate (TEOS)., Spectrosc. Lett. 31 (1998) 199-219.

[35] B. Julian, C. Gervais, E. Cordoncillo, P. Escribano, F. Babonneau, C. Sanchez, Synthesis and characterization of transparent PDMS-metal-oxo based organic anorganic nanocomposites, Chem. Mater. 15 (2003) 30263034 . 
[36] C.J. Brinker, G.W. Scherer, Sol-gel science: the physics and chemistry of sol-gel processing, Academic Press, Boston, 1990.

[37] H. Aguiar, J. Serra, P. Gonzalez, B. Leon, Structural study of sol-gel silicate glasses by IR and Raman spectroscopies, J. Non. Cryst. Solids. 355 (2009) 475-480.

[38] M. Alexandru, M. Cazacu, A. Nistor, V.E. Musteata, I. Stoica, C. Grigoras, et al., Polydimethylsiloxane/silica/titania composites prepared by solventfree sol-gel technique, J. Sol-Gel Sci. Technol. 56 (2010) 310-319.

[39] V.A. Zeitler, C.A. Brown, The Infrared Spectra of Some Ti-O-Si, Ti-O-Ti and Si-O-Si Compounds, J. Phys. Chem. 61 (1957) 1174-1177.

[40] J. Ortega, C. Gonzalez, J. Peña, S. Galván, Thermodynamic study on binary mixtures of propyl ethanoate and an alkan-1-ol (C2-C4). Isobaric vapor-liquid equilibria and excess properties, Fluid Phase Equilib. 170 (2000) 87-111.

[41] J. Brus, Solid-state NMR study of phase separation and order of water molecules and silanol groups in polysiloxane networks, J. Sol-Gel Sci. Technol. 25 (2002) 17-28.

[42] J. Brus, J. Dybal, Hydrogen-Bond Interactions in Organically-Modified Polysiloxane Networks Studied by 1D and 2D CRAMPS and DoubleQuantum ${ }^{1} \mathrm{H}$ MAS NMR, Macromolecules. 35 (2002) 10038-10047.

[43] E. Leonova, I. Izquierdo-Barba, D. Arcos, A. López-Noriega, N. Hedin, M. Vallet-Regí, et al., Multinuclear Solid-State NMR Studies of Ordered Mesoporous Bioactive Glasses, J. Phys. Chem. C. 112 (2008) 55525562.

[44] P.N. Gunawidjaja, R. Mathew, A.Y.H. Lo, I. Izquierdo-Barba, A. Garcia, D. Arcos, et al., Local structures of mesoporous bioactive glasses and their surface alterations in vitro: inferences from solid-state nuclear magnetic resonance, Philos. Trans. R. Soc. A Math. Phys. Eng. Sci. 370 (2012) 1376-1399.

[45] Q. Deng, W. Jarrett, R.B. Moore, K.A. Mauritz, Novel Nafion/ORMOSIL hybrids via in situ sol-gel reactions: 2. Probe of ORMOSIL phase nanostructure by ${ }^{29} \mathrm{Si}$ solid state NMR spectroscopy, J. Sol-Gel Sci. Technol. 7 (1996) 177-190.

[46] F. Babonneau, Si-29, O-17 Liquid Nmr and Si-29 Cp-Mas Nmr Characterization of Siloxane-Oxide Materials, $\left[\left(\mathrm{CH}_{3}\right)_{2} \mathrm{SiO} / \mathrm{TiO}_{2}\right.$, $\left.\left(\mathrm{CH}_{3}\right)_{2} \mathrm{SiO} / \mathrm{ZrO}_{2}\right]$, Mater. Res. Soc. Symp. Proceedings, Better Ceram. through Chem. Vi. 346 (1994) 949-960.

[47] F. Babonneau, N. Baccile, G. Laurent, J. Maquet, T. Azais, C. Gervais, et al., Solid-state nuclear magnetic resonance: A valuable tool to explore 
organic-inorganic interfaces in silica-based hybrid materials, Comptes Rendus Chim. 13 (2010) 58-68.

[48] M. Cypryk, Y. Apeloig, Mechanism of the acid-catalyzed Si-O bond cleavage in siloxanes and siloxanols. A theoretical study, Organometallics. 21 (2002) 2165-2175.

[49] F. Babonneau, J. Maquet, Nuclear magnetic resonance techniques for the structural characterization of siloxane-oxide hybrid materials, Polyhedron. 19 (2000) 315-322.

[50] H. Bale, P. Schmidt, Small-Angle X-Ray-Scattering Investigation of Submicroscopic Porosity with Fractal Properties, Phys. Rev. Lett. 53 (1984) 596-599.

[51] X. Zhang, H. Ye, B. Xiao, L. Yan, H. Lv, B. Jiang, Sol-Gel Preparation of PDMS/Silica Hybrid Antireflective Coatings with Controlled Thickness and Durable Antireflective Performance, J. Phys. Chem. C. 114 (2010) 19979-19983.

[52] X.-X. Zhang, B.-B. Xia, H.-P. Ye, Y.-L. Zhang, B. Xiao, L.-H. Yan, et al., One-step sol-gel preparation of PDMS-silica ORMOSILs as environment-resistant and crack-free thick antireflective coatings, J. Mater. Chem. 22 (2012) 13132.

[53] O. Glatter, O. Kratky, Small angle x-ray scattering, Academic Press, London; New York, 1982.

[54] G. Beaucage, Approximations Leading to a Unified Exponential/PowerLaw Approach to Small-Angle Scattering, J. Appl. Crystallogr. 28 (1995) 717-728.

[55] G. Beaucage, Small-Angle Scattering from Polymeric Mass Fractals of Arbitrary Mass-Fractal Dimension, J. Appl. Crystallogr. 29 (1996) 134146.

[56] D.W. Schaefer, Polymers, Fractals, and Ceramic Materials, Science 243 (1989) 1023-1027.

[57] F.M.A. Margaca, I.M. Miranda Salvado, J. Teixeira, Small angle neutron scattering study of silica gels: influence of $\mathrm{pH}$, J. Non. Cryst. Solids. 258 (1999) 70-77.

[58] B. Julian, C. Gervais, M.N. Rager, J. Maquet, E. Cordoncillo, P. Escribano, et al., Solid-state O-17 NMR characterization of PDMS- $\mathrm{M}_{\mathrm{x}} \mathrm{O}_{\mathrm{y}}$ $(\mathrm{M}=\mathrm{Ge}(\mathrm{IV}), \mathrm{Ti}(\mathrm{IV}), \mathrm{Zr}(\mathrm{IV}), \mathrm{Nb}(\mathrm{V})$, and $\mathrm{Ta}(\mathrm{V}))$ organic- inorganic nanocomposites, Chem. Mater. 16 (2004) 521-529. 
[59] L. Crouzet, D. Leclercq, P.H. Mutin, A. Vioux, Organosilsesquioxanetitanium oxide hybrids by nonhydrolytic sol-gel processes. Study of the rearrangement of Si-O-Ti bonds, Chem. Mater. 15 (2003) 1530-1534.

[60] D.W. Schaefer, K.D. Keefer, Structure of Random Porous Materials Silica Aerogel, Phys. Rev. Lett. 56 (1986) 2199-2202.

[61] M. Kallala, R. Jullien, B. Cabane, Crossover from gelation to precipitation, J. Phys. II. 2 (1992) 7-25.

[62] T.A. Ulibarri, G. Beaucage, D.W. Schaefer, B.J. Olivier, R.A. Assink, Molecular Weight Dependence of Domain Structure in Silica-Siloxane Molecular Composites, MRS Proc. 274 (2011) 85.

[63] R.H. Glaser, G.L. Wilkes, Structure Property Behavior of Polydimethylsiloxane and Poly(Tetramethylene Oxide) Modified Teos Based Sol-Gel Materials .5. Effect of Titaniumisopropoxide Incorporation, Polym. Bull. 19 (1988) 51-57.

[64] C. Guermeur, J. Lambard, J.F. Gerard, C. Sanchez, Hybrid polydimethylsiloxane-zirconium oxo nanocomposites. Part 1 Characterization of the matrix and the siloxane-zirconium oxo interface, J. Mater. Chem. 9 (1999) 769-778.

[65] J. Jopp, H. Grüll, R. Yerushalmi-Rozen, Wetting behavior of water droplets on hydrophobic microtextures of comparable size., Langmuir. 20 (2004) 10015-9.

[66] Christophe Drouet, Apatite formation: why it may not work as planned, and how to conclusively identify apatite compounds., Biomed Res. Int. 2013 (2013) 12 pages.

[67] A. Checco, P. Guenoun, J. Daillant, Nonlinear dependence of the contact angle of nanodroplets on contact line curvature., Phys. Rev. Lett. 91 (2003) 186101.

[68] L. Bacakova, E. Filova, M. Parizek, T. Ruml, V. Svorcik, Modulation of cell adhesion, proliferation and differentiation on materials designed for body implants., Biotechnol. Adv. 29 (2011) 739-67.

[69] A.C. Lima, J.F. Mano, Micro-/nano-structured superhydrophobic surfaces in the biomedical field: part I: basic concepts and biomimetic approaches., Nanomedicine (Lond). 10 (2015) 103-19.

[70] L. Bacáková, E. Filová, F. Rypácek, V. Svorcík, V. Starý, Cell adhesion on artificial materials for tissue engineering., Physiol. Res. 53 Suppl 1 (2004) S35-45.

[71] R.K. Assoian, E.A. Klein, Growth control by intracellular tension and extracellular stiffness., Trends Cell Biol. 18 (2008) 347-52. 
[72] M.M. Stevens, J.H. George, Exploring and engineering the cell surface interface., Science. 310 (2005) 1135-8.

[73] M. Pérez Olmedilla, N. Garcia-Giralt, M.M. Pradas, P.B. Ruiz, J.L. Gómez Ribelles, E.C. Palou, et al., Response of human chondrocytes to a nonuniform distribution of hydrophilic domains on poly (ethyl acrylate-cohydroxyethyl methacrylate) copolymers., Biomaterials. 27 (2006) 100312. 